\title{
Mechanical Properties of Sandwich Panels Constructed from Polystyrene/Cement Mixed Cores and Thin Cement Sheet Facings
}

\author{
Hamid Reza Tabatabaiefar ${ }^{1 *}$, , Bita Mansoury ${ }^{2}$, Mohammad Javad Khadivi Zand ${ }^{2}$ and \\ Daniel Potter ${ }^{1}$ \\ 1- Faculty of Science and Technology, Federation University Australia, Australia \\ 2- Faculty of Design, Architecture and Building, University of Technology Sydney (UTS), Australia
}

\begin{abstract}
Sandwich panels are made of two materials that are relatively weak in their separated state, but are improved when they are constructed together in a sandwich panel. Sandwich panels can be used for almost any section of a building including roofs, walls and floors. These building components are regularly required to provide insulation properties, weatherproofing properties and durability in addition to providing structural load bearing characteristics. Polystyrene/cement mixed cores and thin cement sheet facings sandwich panels are Australian products made of cement-polystyrene beaded mixture encapsulated between two thick cement board sheets. The structural properties of sandwich panels constructed of polystyrene/cement cores and thin cement sheet facings are relatively unknown. Therefore, in this study, in order to understand the mechanical behaviour and properties of those sandwich panels, a series of experimental tests have been performed and the outcomes have been explained and discussed. Based on the results of this study, values for modulus of elasticity and ultimate strength of the sandwich panels in dry and saturated conditions have been determined and proposed for practical applications.
\end{abstract}

Keywords: Sandwich Panels, Polystyrene/Cement Mixed Cores, Thin Cement Sheet Facings, Modulus of Elasticity, Ultimate Strength

\section{INTRODUCTION}

The building and construction industry is ever increasing in size and the demand for houses and industrial buildings all around Australia is currently greater than ever (Australian Bureau Statistics, 2015a). The growing amount of houses and industrial buildings being constructed is affecting the amount of building materials being produced and is influencing the competitive prices needed to complete these constructions (Australian Bureau Statistics, 2015b). The demand for building materials has prompted the development of construction products and methods. These construction products have been carefully thought out with careful considerations for the future. The environment, the purpose and efficiency of materials are all considerations that are continually thought of in the development of these materials. The considerations for the future and the effects on the environment are the main reasons why people produce construction materials. One of these construction materials are sandwich panels. Sandwich panels are made of two materials that are relatively weak in their separated state, but are improved when they are constructed together in a

\footnotetext{
* Correspondence to: Hamid Reza Tabatabaiefar, Lecturer in Structural Engineering, Federation University Australia, Office Y231, Building Y, Mt Helen Campus, PO Box 663 Ballarat VIC 3353, Australia, Tel.: +61 353276718

† E-mail address: h.tabatabaiefar@federation.edu.au.
} 
sandwich panel (Allan, 1969). Sandwich panels can be used for almost any section of a building. The sections include the roof, the walls and the floor. These building sections are regularly required to provide insulation properties, weatherproofing properties and durability in addition to providing structural load bearing characteristics (Petras, 1998). It is usually very common to find precast concrete panels as a part of a building's composition. Precast concrete panels are normally very strong, but are generally extremely heavy and difficult to work with.Sandwich construction form has distinct advantages over conventional structural sections because it promises high stiffness and high strength-to-weight ratio (Araffa and Balaguru, 2006) as compared with a solid member. Sandwich composite structure possesses excellent flexural and shear properties. Their inherent lightweight characteristics make them ideal structural components where weight reduction is desirable (Serrano et al., 2007). Thus structural sandwich panels are becoming important elements in modern lightweight construction. Among the other advantages, its good thermal insulation due to the cellular thick core makes it an ideal external construction component (Bottcher and Lange, 2006). Some recent investigations suggest their excellent energy-absorbing characteristics under high-velocity impact loading conditions (Villanueva and Cantwell, 2004). Sandwich structures have been considered as potential candidate to mitigate impulsive (short duration) loads (Nemat-Nasser et al., 2007).

With the building requirements and the disadvantages of precast concrete panels, sandwich panels provide an alternative to the precast concrete panels. There are many different types of composite sandwich panels that can be constructed, but one of the stronger types of sandwich panels is a panel made of a polystyrene/cement core that is sandwiched between thin cement sheet facings (Davies, 1993). The structural properties of sandwich panels constructed of polystyrene/cement cores and thin cement sheet facings are relatively unknown (Mousa \& Uddin, 2010). Therefore, there are a number of questions that could be asked such as how the stress acts within the panel under loads? How they are affected by moisture and what is the effect of a sustained load? Besides, the stresses acting within the panel are the stresses acting in the different materials within the panel. These stresses are unknown and an understanding of the amount of stress carried by each of the core and the facings components would be beneficial to provide a better awareness of the stresses acting and possibly provide information that could be used to improve these panels. As results, in this study, in order to understand the mechanical behaviour and properties of sandwich panels made of polystyrene/cement mixed cores and thin cement sheet facings, a series of experimental tests have been performed at the structures laboratory of Federation University Australia and the outcomes have been explained and studied in this paper.

\section{BACKGROUND}

Composite sandwich panels have gradually become more popular due to their typical benefits including strength, weight, ease of handling, durability, versatility, thermal and acoustic properties (Gdoutos and Daniel, 2008). Many researchers are aware of these benefits and have undertaken detailed research and publicised large amounts of scientific papers on composite panels. Zenkert (1995) introduced sandwich constructions as materials 
structured in a way that the bending stresses are supported by the face-sheets and the core supports the shear loads and stabilises in order to influence wrinkling or buckling acting against the face. Petrras (1998) investigated the failure modes for sandwich beams with a range of varied thickness laminate skins and honeycomb cores under a number of loading combinations to determine skin and core behaviour and comparing the results with sandwich beam theory. Daienl et al. (2002) elucidated failure modes of composites sandwich beams which revealed different failures of composite panels. These include compressive face sheet failure, face sheet debonding, indentation failure and core failure and face sheet wrinkling. In concrete construction, self-weight of structure itself represents a very large proportion of the total load on the structures (Mouli and Khelafi, 2006; Tabatabaiefar et al., 2014a,b). Thus, reduction in the self-weight of the structures by adopting an appropriate approach results in the reduction of element cross-section, size of foundation and supporting elements thereby reduced overall cost of the project. The lightweight structural elements can be applied for construction of the buildings on soils with lower load-bearing capacity (Carmichael, 1986). Reduced self-weight of the structures using lightweight concrete reduces the risk of earthquake damages to the structures because the earth quake forces that will influence the civil engineering structures and buildings are proportional to the mass of the structures and building. Thus reducing the mass of the structure or building is of utmost importance to reduce their risk due to earthquake acceleration (Ergul et al., 2004; Tabatabaiefar et al., 2015a,b).

Gdoutos and Daniel (2008) detailed how composite sandwich panels are made of a core and two skin layers that are fixed to either side of the core. The core material is generally a lighter material where the thin skin layers are generally the stronger and stiffer. They investigated failure modes of composite sandwich beams made of unidirectional carbon/epoxy facings and PVC closed-cell foam cores which revealed different failures of composite panels, which is described as dependent upon factors such as the materials properties of the skin and the core, the dimensions of the test samples and the types of load combinations applied. Followed by Gdoutos and Daniel (2008), Manalo (2010) compared the failure mechanism and ultimate strength of structural fibre composite sandwich beams loaded in an edgewise position compared to a flatwise position and acknowledges the contribution of the strength of the core material on flexural and shear stiffness of the composite sandwich while Plain (2009) studied the behaviour of fibre composite sandwich panels for use in the civil infrastructure and building industry through a number of varied point and uniformly distributed load testing conditions to gain material properties for development of analytical design modelling. The above research outcomes haves highlighted a number of differing properties of the derivatives of sandwich panels and identified a number of differing failure modes to consider in conducting destructive testing models for the thin faced reinforced concrete with polystyrene concrete core panels being tested and analysed. 


\section{POLYSTYRENE/CEMENT CORE \& CEMENT FACINGS SANDWICH PANELS}

Polystyrene/Cement Core and Cement Facings Sandwich Panels (Figure 1a) are Australian products made of cement-polystyrene beaded mixture encapsulated between two $6 \mathrm{~mm}$ thick cement board sheets. They can be purchased in thicknesses of $50 \mathrm{~mm}$ thick or $75 \mathrm{~mm}$ thick and are constructed with a width of $600 \mathrm{~mm}$ and a range of lengths, with the maximum length being $6.0 \mathrm{~m}$. The panels are typically produced in lengths of $2600 \mathrm{~mm}$ and $3000 \mathrm{~mm}$. The panels are normally orientated so that the short edge is at the bottom or top and are installed by sliding the panel between top and bottom steel channels and are fixed together with a grooving fixture and a tongue (Figure 1b). These types of panels are used by the industry as they are light-weight and easier to handle/install than more traditional panel designs. The panels are easily transported and handled on-site reducing the cost of construction and they are termite, pest and rot resistant contributing to its long term performance in buildings. In addition, the panels have better thermal, acoustic and fire resistant properties than traditional building materials used in the building industry (Zenkert, 1995).

Reviewing the past research outcomes in Section 2, a greater understanding of the makeup and considerations for design and use of sandwich panels has been developed encouraging the scope of this study to be refined with the aim of determining three main components:

- Investigating the true stress distributions acting within the sandwich panels under the applied loads;

- Determining the effects of moisture content of the mechanical properties of the panels; and

- $\quad$ Elucidating the effects of sustained loads (creep effects).

The ultimate goal of this study is to investigate and analyse the structural properties of composite sandwich panels comprising thin outer cement sheeting layers on either sides of the core having cement paste and polystyrene beads. The investigation and analyses will further develop an understanding of the behaviour and properties of Polystyrene/Cement Core and Cement Facings Sandwich Panels.

\section{MATERIAL CHARACTERISTICS}

The flexural stiffness of a material is measured with the Modulus of Elasticity (E). The modulus of elasticity for a rectangular beam that is simply supported with a mid-span load (P) can be determined by using the equation for maximum deflection and the slope of the load versus the displacement graph, where the slope is within the linear zone of the graph as shown in Figure 2. The maximum deflection equation for a simply supported rectangular beam is:

$$
D=\frac{P L^{3}}{48 E I}
$$

where $D$ is the maximum deflection of the beam; $P$ is the mid-span load; $E$ is the modulus of elasticity and $I$ is the moment of inertia of the section. 
By rearranging Equation 1, Hilbbeler (1994) presented Equation 2 for determining the modulus of elasticity:

$$
E=\left(\frac{P}{D}\right)\left(\frac{L^{3}}{4 a b^{3}}\right)
$$

where, $I=\frac{a b^{3}}{12}$ and $a$ and $b$ are the cross sectional dimensions, respectively.

The flexural strength of the panel can be calculated from simple bending theory. For a simply supported beam with a midpoint load, the equation for stress with relation to bending is:

$$
\sigma=\frac{M y}{I_{x}}
$$

where, $\sigma$ is the normal stress; $M$ is the bending moment; $y$ is the distance from neutral axis and $I_{X}$ is the moment of inertia for a rectangular section.

Equation 3 is called the Bending Formula (Gross et al., 2011) which assumes a homogeneous material with stress diagram shown in Figure 3a. As the panels are not homogeneous, the stress distribution within the panel looks more like the stress diagram in Figure 3b. To determine the stresses acting within a sandwich panel, the elasticity modulus of the separate core component and the separate face sheeting component are needed. As the bending formula assumes a uniform material, one of these different material areas need to be changed into effective area of the other materials modulus. This is done by using a ratio of the modulus of elasticity's to convert the area of one of the materials. Figure 4a illustrates a normal sandwich panel with materials of different moduli and Figure $4 \mathrm{~b}$ shows a converted effective area with material of one elastic modulus (Gross et al., 2011). The ratio used to convert the smaller elastic modulus into the larger elastic modulus to create Figure 4b (Gross et al., 2011) is:

$$
\frac{E_{\text {Poly }}}{E_{\text {Conc }}} \times b_{\text {Poly }}=b_{\text {ef }}
$$

where, $E_{\text {Poly }}$ is the elastic modulus of the polystyrene material; $E_{\text {Conc }}$ is the elastic modulus of the concrete material; $b_{\text {poly }}$ is the width of the polystyrene material and $b_{e f}$ is the effective width.

The moment of Inertia (I) can then be calculated for the new effective shape by using the "parallel axis theorem" (Hibbeler, 1994). This can be done using Eq. 5 as follows:

$$
I_{\text {Total }}=\sum\left(I_{i}+A_{i} d_{i}^{2}\right)
$$

where, $I_{i}$ is the moment of inertia of an individual shape about its own centroid axis, $A_{i}$ is the area of an individual shape and $d_{i}$ is the distance of an individual shape to the neutral axis. 
This total moment of inertia $\left(I_{\text {Total }}\right)$ can be used along with the calculated bending moment at mid-span in the "Bending Formula" (Eqn. 3) to give the max stresses in the top and bottom of the panel (Hibbeler, 1994). The stresses at the join between the sheeting and core can be also calculated. These calculated stresses then may be converted into strain using the effective shapes modulus by using:

$$
E=\frac{\text { Stress }}{\text { Strain }}
$$

These strains are then multiplied by the modulus of the existing core material to produce stress diagrams similar to like Figure 3a.

\section{MATERIAL TESTING PROGRAM}

The testing of the samples in the testing program has been broken up into different stages. These stages were the sample preparation, testing for true stresses, testing for effect of moisture and the creep testing. These stages are outlined below.

\subsection{Test Sample Preparation}

The testing of samples required large $1.5 \mathrm{~m} \times 0.6 \mathrm{~m}$ panels to be cut to a size that could be managed by the testing apparatus at the structures laboratory of Federation University Australia. Several samples were required to be separated into their different components (core and facing). The sample preparation was a large task and therefore was broken up into three different sections. These were the cutting of the whole sample panels, cutting of the core components and cutting of the facing components. The cutting of these materials was conducted with the use of a circular saw with a diamond tip blade which could cut through $75 \mathrm{~mm}$ think panels, a drop saw with a diamond tip blade which could cut through $75 \mathrm{~mm}$ thick panels and had a reach of $300 \mathrm{~mm}$ minimum and, an angle grinder with a stone disk. Protective equipment of ear muffs, glasses and a breathing mask were also worn due to the amount of dust and debris. The panels were first carefully measured with a tape and a square. They were then clamped and cut using the circular saw (Figure 5) and then re-measured to make sure the sample was within a \pm $1 \mathrm{~mm}$. All sandwich samples were cut and prepared using this method. The next stage in cutting used the drop cut saw to either cut the sheeting off the core (Figure 6) if requiring separate core component or cut the core off the sheeting if requiring the sheeting component. This process has completed the separating of the core component and the sheeting has been discarded. The final cutting of the samples required the use of the angle grinder to finely grind off the excess core material to leave just the cement sheeting (Figure 7). All of these samples were produced with millimetre accuracy to provide accurate results as illustrated in Figure 8.

\subsection{Stresses within the Panel Testing}

The stresses acting within the sandwich panels were researched by conducting several tests. These tests included testing of whole specimens, testing on the separated core specimens and testing on the separated facing specimens. These tests determined the flexural strength and the flexural stiffness of the materials. The three types of 
specimens were all tested in bending in a horizontal flexural test. The horizontal flexural tests for the whole specimens were carried out in the structures laboratory of Federation University Australia. The test sample size and the arrangement were guided by ASTM International (2012). The standards stated that the standard size of testing sample of sandwich nature to be $600 \mathrm{~mm} \times 75 \mathrm{~mm}$ and have either a 4-point loading configuration or a 3-point loading configuration.

\subsubsection{Whole Sample Testing}

Firstly, the 3-point loading configuration was used with a $600 \mathrm{~mm} \times 75 \mathrm{~mm}$ sample spaned 560mm with a midpoint load. The equipment used to setup the first sample in the mid-span loading included two support posts, a clamped steel beam between the two supports to make the support posts ridged, one locked simple support roller, one simple support roller, hanger that supports the load across the sample evenly (Figure 9a), hanger to support the load (Figure 9b), three deflectometers and three small pieces of flat steel. The three deflectometers were setup with one at each end of the sample over the support and one at $15 \mathrm{~mm}$ from mid-span due to the hanger preventing the deflectometer from being at mid-span (Figure 10a). This small variance from mid-span was estimated to give very little error and was ignored. The sample was also setup with a small piece of $40 \times 6 \times 100 \mathrm{~mm}$ flat steel under the supports to prevent the supports from crushing into the sample and giving a wrong reading at the mid-span (Figure 10b). The middle hangers also included a small $20 \times 10 \times 100 \mathrm{~mm}$ flat steel to prevent the round hanger pressing into the sample and causing a premature failure.

After the sample was setup in the apparatus, the sample was observed for deflection due to self-weight, deflection due to load of hanger 1 (Figure 9a) and deflection due to load of hanger 2 (Figure 9b). The increasing load on the sample was then applied by placing $8 \mathrm{~kg}$ weights on hanger 2 and recording the deflections on all of the deflectometers. The recorded deflections on the deflectometers over the supports were generally very little and have been averaged and subtracted from the total deflection at the supports.

As the second testing method, testing the whole samples was undertaken using the Automax Smart Line control system with a flexure frame made by Controls Group (Figure 11). This compression/flexure machine uses a hydraulic pump and ramp to supply a load of between $0 \mathrm{kN}$ and $5000 \mathrm{kN}$ (Controls Group, 2014). According ASTM International (2012) the test samples were arranged in a 2-point loading and 2 support load configuration. The standards stated the 4-point loading configuration as a sample spaned 560mm across a simply support and a roller support with the middle 2 loads $100 \mathrm{~mm}$ apart. The 4-point loading apparatus was also setup (Figure 12) with three deflectometer's, one at each end over the supports, and one at mid-span. As illustrated in Figure 12, the mid-span deflectometer was unable to be put directly in the middle of the sample due to the loading ram. This issue was overcome by clamping a light piece of angled aluminium to the top of the sample that protruded to the left of the sample so that the delectometer could be attached. This arrangement was considered as having very minimal effects on the results. The apparatus also included two flat pieces of steel (7mm thick) that were placed between the sample and the round support (Figure 13). These flat pieces of steel were placed there to reduce the round supports from 
compressing up into the sample and causing inaccurate results. The deflection due to self-weight was also observed and recorded. The loads were then applied in $0.5 \mathrm{kN}$ increments and deflections were recorded. It should be noted that it means each time $0.5 \mathrm{kN}$ has been added then the corresponding deflection was measured and recorded. The two deflectometers over the supports were averaged and substituted from the midspan deflection. The deflection verse load was plotted.

The third and final method used to in testing of the whole samples was using the Automax control system with the flexure frame with 3-point arrangement as shown in Figure 14. The load was applied in $0.5 \mathrm{kN}$ increments and the deflections recorded until the failure of the sample. The deflection versus load was plotted and the slope of the elastic region of the graph was used in the rearranged deflection equation (Eqn. 2) to determine the elastic modulus $(E)$. As mentioned in Section 4, the employed panels are not made of homogeneous materials. Therefore, the calculated moduli of elasticity for the whole panels are not the true moduli. The true moduli of the materials within the sandwich panels were calculated by testing the separated core component and testing of the separated face sheeting component as will be explained in Section 5.2.2. Eventually, the flexural strengths of the panels were determined by finding the stresses acting within each material by means of the method explained in Section 4.

\subsubsection{Core Sample Testing}

After initially testing the whole samples, it was clear that the testing machine would not be ideal for the testing of the separate sections due the increments of load that the machine could be applied (only dealing with larger increments). Therefore a different apparatus was required. The utilised apparatus was a 3-point loading apparatus with manual weights connected to the hangers at the mid-span, which was the same setup as the first method of testing the whole samples, explained in Section 5.2.1. As shown in Figure 15, the 3-point apparatus used the three deflectometer's with two at the supports and one at the mid-span located $15 \mathrm{~mm}$ next to the hanger. The same flat steel plates ( $7 \mathrm{~mm}$ thick) were also utilised under the supports. Deflections due to self-weight, load of the hangers and an increasing $1 \mathrm{~kg}$ weights at mid-span were measured and recorded. The loads versus deflections graphs were plotted afterwards and the moduli of elasticity were determined according to Section 4.

\subsubsection{Face Sheeting Sample Testing}

The face sheeting samples testings have been performed using the same 3-point loading configuration as the core component tests (Figure 16). Deflections due to self-weight, load of the hangers and an increasing $0.4 \mathrm{~kg}$ weights at mid-span were measured and recorded. The loads versus deflections graphs were plotted afterwards and the moduli of elasticity were determined according to Section 4.

\subsection{Effects of Moisture Content}

The tests on the effects of water were conducted in a similar apparatus as the tests of the stresses within the panels. The tests were performed by soaking the whole samples over a 6 month period, testing the bending strength of the panels and eventually comparing the results with the results obtained from the dry samples. The samples were $600 \mathrm{~mm} \times$ 
$75 \mathrm{~mm} \times$ thickness of the panel $(75 \mathrm{~mm})$. These were weighed and recorded before submerging the samples in order to measure the amount of absorbed moisture. Figure 17 shows a saturated sample in 3-point loading using Automax control system and the flexure frame apparatus. One interesting observation was that samples floated when they were placed in the water and bricks were needed to fully submerge them (Figure 18).

\subsection{Creep Effects}

In order to determine the flexural creep of the material, tests were performed according to ASTM International (2008). The effect of creep was planned to be observed by creating 6 creep apparatuses and testing the effect of a load over a 10 week period to determine the creep rate of the panel. Preliminary destruction testing of the creep test panels was undertaken by first testing four $900 \times 75 \times 75 \mathrm{~mm}$ simply supported samples (860mm span) to obtain the average ultimate strength of the panels $(1.4 \mathrm{kN})$. It should be noted that the main reason for testing four samples in the testing program was to show repeatability of the test results and to achieve reliable average values. Other research was considered along with the panel's modulus of elasticity to determine the appropriate percentage of the ultimate strength loading to be placed on the creep test samples.

\section{RESULTS AND DISCUSSION}

The experimental measurements of each set of tests, explained in Section 5, are outlined in this section. The load-deflection results for four different core samples and four different face sheeting samples are measured and shown in Figures 19 and 20. From those Figures, the slope of each load-deflection graph has been determined and the modulus of elasticity was calculated. The calculated moduli of elasticity and ultimate strengths for core and face sheeting samples are summarised in Tables 1 and 2. Based on the summarised results, the average values for modulus of elasticity and ultimate strength of the core samples are $400 \mathrm{MPa}$ and $210 \mathrm{~N}$, respectively while these values are determined to be respectively $10890 \mathrm{MPa}$ and $47.8 \mathrm{~N}$ for the face sheeting samples.

Figure 21 shows the whole sample tests results, were tested in a 4-point loading arrangement with the Automax controls system and flexure flame. These results have not been taken into consideration as several data points were predicted to be incorrect due to the apparatus and movement of the samples. The issues involved with the 4-point loading configuration were overcome with the test in the 3-point loading configuration. The results from the 3 -point configuration for the $600 \times 75 \mathrm{~mm}$ samples are illustrated in Figure 22. From this Figure, the slope of each sample was determined and the modulus of elasticity for each sample has been calculated accordingly. The calculated moduli of elasticity and ultimate strengths are summarised in Table 3. It should be noted that it was chosen to work out the elastic modulus for each sample instead of plotting one trend line for all the data. This is due to the material being non-homogenise and a range of moduli would be a better result for the other researchers to use in the future. As mentioned in Section 4, the modulus of elasticity was determined by plotting all of the samples tested and plotting a trend line (line of best fit) and determining the loaddeflection slope to sub into the equations. Based on the summarised results in Table 3, 
the average values for modulus of elasticity and ultimate strength of the whole samples are $4180 \mathrm{MPa}$ and $2000 \mathrm{~N}$, respectively. These values are recommended be adopted for practical design applications.

According to Zhu and Chai (2013), three main failure modes for sandwich panels exist, namely, facing fracture, core shear yield/fracture and overall core crushing. The mode in which a sandwich panel structure fails on loading can be determined by establishing, for a given panel geometry and materials properties, which mechanism has the lowest failure load. This information can be plotted on a failure diagram where regions of the diagram correspond to a given failure mechanism. In order to determine the failure mode of the sandwich panels in this study, the stresses within a panel were determined by using the method described in Section 4. Using the modulus of 400MPa for the core material and 10,900MPa for the face sheeting, the true stress diagram has been plotted for sample A10 at failure (Figure 23). As shown in Figure 24, the typical failure mode of the $600 \times 75 \mathrm{~mm}$ sandwich panel occurred when the bottom cement facing failed leading it to crack and protrude upwards. Therefore, the main failure mode of the studied panels is facing fracture. As the thickness of facings of the examined panels are thin compared to the other dimensions of the panels and considering that the cores are of sufficient stiffness, the global deflections of the sandwich panels tend to be large and as a result, there arise high in-plane tensile forces that will cause tensile cracking. As a result, the cores have insignificant effect on the failure of the panels in bending until the outer tension faces fail causing the cores to fail in a catastrophic mode.

The results from the fully saturated panel samples are shown in Figure 25. Similar to the previous components, the slope of each load-deflection graph has been found and the modulus of elasticity was determined. The calculated moduli of elasticity and ultimate strengths are summarised in Table 4. Based on the summarised results, the average values for modulus of elasticity and ultimate strengths of the fully saturated panel samples are $4466 \mathrm{MPa}$ and $1312 \mathrm{~N}$, respectively. These results show that the fully saturated panels possess larger moduli of elasticity. However, due to saturation, their ultimate strengths reduce substantially.

Preliminary destruction testing of the creep test panels were undertaken by testing four $900 \times 75 \times 75 \mathrm{~mm}$ simply supported samples that were to obtain the average ultimate strength of the panels. The percentage of ultimate strength loading was determined to be $75 \%$ of the ultimate strength load, as it was appropriately within the range of previous research conducted being 65\% for wood and $85 \%$ for concrete. Three preliminary creep tests were conducted by using a set of constructed apparatus that simply supported the samples over a 2 week period. The samples were setup with the $75 \%$ of the ultimate strength at the midpoint with the deflection recorded while the time increased. Based on the summarised results in Table 5 , the $75 \%$ of the ultimate strength at the midpoint is 1040 N. It is understood that the creep testing was unable to provide conclusive results as the deflection results from preliminary testing did not produce significant deflection of the samples to measure enough to undertake the longer term tests. 


\section{CONCLUSIONS AND RECOMMENDATIONS}

In this study, the true stresses acting within typical cement sheet faced cemented polystyrene core composite sandwich panels have been measured and studied. The main finding that this investigation has highlighted is the strengths of the composite sandwich panels in bending are highly dependent on the strength of the outer cement face sheeting. Primarily, the ultimate strengths can be determined by determining the tensile strengths of the tension faces of the panels. Therefore, the cores have insignificant effect on the failure of the panels in bending until the outer tension faces fail causing the cores to fail in a catastrophic mode. Based on the results of this study, the average values for modulus of elasticity and ultimate strength of polystyrene/cement core and cement facings sandwich panels are $4180 \mathrm{MPa}$ and $2000 \mathrm{~N}$, respectively. These values can be adopted for practical applications. In addition, saturating the sandwich panels reduce the strength of the outer facings resulting in $28 \%$ reduction in the total strength compared to dry samples.

The creep testing in this study was unable to provide conclusive results as the deflection results from preliminary testing did not produce significant deflection of the samples to measure enough to undertake the longer term tests. As a result, further investigation could be undertaken on the creep of the panels with consideration to the size of the panel to get greater deflections and more discernible results.

Results of some recent research works on combination of cement, fibre and clay (Fatahi et al., 2012; Fatahi et al., 2013) show that addition of fibre can increase the strength and stiffness and reduce the shrinkage potential of the composite material. Therefore, it is recommended that further studies and experimental works to be carried out on the effects of addition of fibre on the strength, stiffness and shrinkage potential of Polystyrene/Cement Core and Cement Facings Sandwich Panels. 


\section{References}

Allan, H. (1969). Analysis and Design of Structural Sandwich Panels. London, United Kingdom: Pergamon Press Ltd.

Araffa, M. and Balaguru, P.N. (2006). Flexural Behaviour of High Strength-High Temperature Laminate Sandwich Beams. Proceedings of Eight International Symposium and Workshop on Ferrocement and Thin Reinforced cement Composites,6-8 February, Bangkok Thailand, IFS.189-201.

ASTM International. (2008). Standard Test Method for Flexure Creep of Sandwich Constructions. West Conshohocken: American Society for Testing and Materials. Retrieved March 5, 2014, from Sai Global.

ASTM International. (2012). Standard Test Method for Facing Properties of Sandwich Constructions by Long Beam Flexure. West Conshohocken: American Society for Testing and Materials. Retrieved March 31, 2014.

Australian Bureau Statistics. (2015a). Population Clock. Retrieved 2015, from Australian Bureau Statistics: http://www.abs.gov.au/ausstats/abs\%40.nsf/94713ad445ff1425ca25682000192af2/1 647509ef7e25faaca2568a900154b63?OpenDocument.

Australian Bureau Statistics. (2015b). Producer Price Indexes. Retrieved 2015, from Australian Bureau Statistics: http://www.abs.gov.au/AUSSTATS/abs@.nsf/Lookup/6427.0Main+Features1Mar \%202015?OpenDocument.

Bottcher, M. and Lange, J. (2006). Sandwich Panels with Openings. Composite Construction in Steel and Concrete, 186(14): 137-46.

Carmichael, J (1986). Pumice Concrete Panels. Concrete International. 8(11): 31- 32.

Controls Group. (2014). Compression Machines. Retrieved 2015, from Controls Group Web site: http://www.controls-group.com/eng/concrete-testing-equipment/automaxsmart-line-fully-automatic-tester.php

Daniel, I., Gdoutos, E., Wang, K., \& Abot, J. (2002). Failure Modes of Composites Sandwich Beams. International Journal of Damage Mechanics, 16, 309-334.

Davies, J. (1993). Sandwich Panels. Thin Walled Structures, 16, 179-198.

Ergul, Y., Cengiz, D.A., Aleaettin, K. and Hassan, G. (2003). Strength and Properties of Lightweight Concrete Made with Basaltic Pumice and Fly Ash. Materials Letters. 57(15): 2267-2270.

Fatahi, B, Khabbaz, H. and Fatahi, B. (2012). Mechanical Characteristics of Soft Clay Treated with Fibre and Cement. Geosynthetics International. 19(3): 252-262.

Fatahi, B, Fatahi, B, Le, T.M. and Khabbaz, H. (2013). Small-Strain Properties of Soft Clay Treated with Fibre and Cement. Geosynthetics International. 20(4), 286-300.

Gdoutos, E., \& Daniel, I. (2008). Failure Modes of Composite Sandwich Beams. Theoretical and Applied Mechanics, 35(1-3), 105-118. 
Gross, D., Hauger, W., Schröder, J., A.Wall, W., \& Bonet, J. (2011). Engineering Mechanics 2. Springer Heidelberg Dordrecht London New York.

Hibbeler. (1994). Mechanics of Materials (2ed.). Macmillan.

Mouli, M. and Khelafi, H. (2006). Strength of Short Composite Rectangular Hollow Section Columns Filled with Lightweight Aggregate Concrete. Engineering Structures. 29 (8):1791-1797.

Mousa, M., \& Uddin, N. (2010). Global Buckling of Composite Structural Insulated Wall Panels. Materials and Design, 32(2), 766-772.

Nemat-Nasser, S., Kang, W.J, Mc Gee, J.D., Guo, E.G. and Isaacs (2007). Experimental Investigation of Energy-Absorption Characteristics of Components of Sandwich Structures. International Journal of Impact Engineering, 34(6): 1119-1146.

Petras, A. (1998). Design of Sandwich Structures. Cambridge University Engineering Department, 1-100.

Plain, M. (2009). Behaviour of Innovative Fibre Composite Panels for Structural Applications. University of Southern Queensland, 1-106.

Serrano, P. J.C, Uday, K.V. and Nasim, U. (2007). Low Velocity Impact Response of Autoclaved Aerated Concrete/CFRP Sandwich Plates. Composite Structures. 80(4): 621-630.

Tabatabaiefar, H.R., Fatahi, B. \& Samali, B. (2014a). An Empirical Relationship to Determine Lateral Seismic Response of Mid-Rise Building Frames under Influence of Soil-Structure Interaction. The Structural Design of Tall and Special Buildings, 23(7): 526-548.

Tabatabaiefar, H.R., Fatahi, B., \& Samali, B. (2014b). Numerical and Experimental Investigations on Seismic Response of Building Frames under Influence of SoilStructure Interaction, Advances in Structural Engineering, 17(1): 109-130.

Tabatabaiefar, H.R., Mansoury, B. \& Khadivi Zand, M.J. (2015a). Experimental Investigations on Behaviour of Steel Structure Buildings. Proceedings of the 10th Pacific Conference on Earthquake Engineering, Australian Earthquake Engineering Society, 6-8 November 2015, Sydney, Australia, Paper Number 160.

Tabatabaiefar, H.R. \& Mansoury, B. (2015b). Detail Design, Building and Commissioning of Tall Building Structural Models for Experimental Shaking Table Tests. The Structural Design of Tall and Special Buildings, DOI: 10.1002/tal.1262, WileyBlackwell.

Villanueva, G.R. and Cantwell, W.J. (2004). The High Velocity Impact Response of Composite and FML-Reinforced Sandwich Structures. Composite Science and Technology. 64(1): 35-54.

Zenkert, D. (1995). An Introduction to Sandwich Construction. West Midlands, United Kingdom: Engineering Materials Advisory Service Ltd.

Zhu, Z. \& Chai, G.B. (2013). Damage and failure mode maps of composite sandwich panel subjected to quasi-static indentation and low velocity impact. Composite Structures. 101:204-214. 


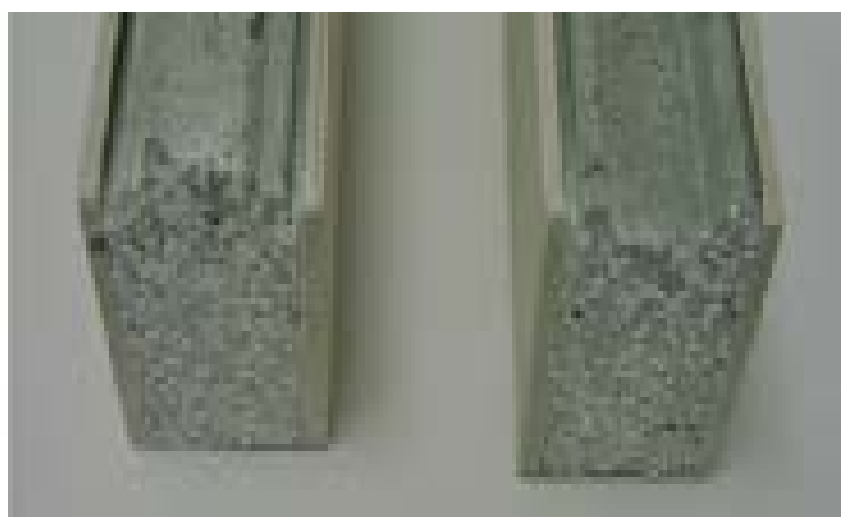

(a)

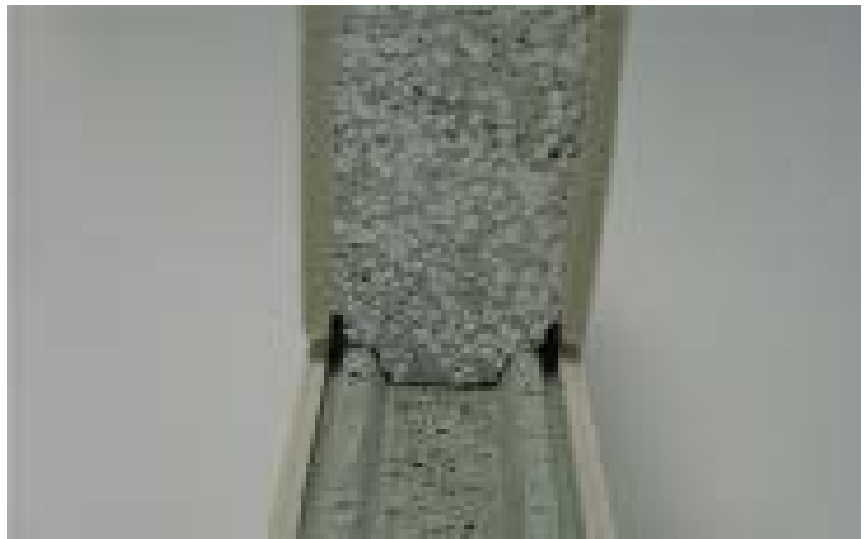

(b)

Figure 1: Cement/Polystyrene Core \& Cement Sheet Facing Sandwich Panels 


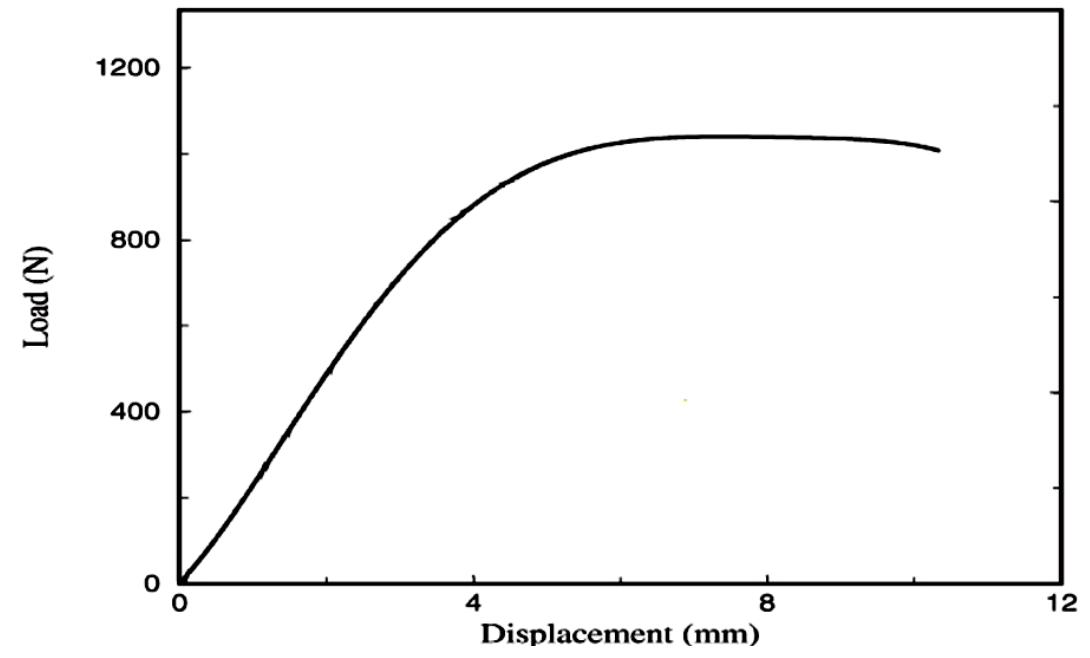

Figure 2: Typical Load-Displacement graph 


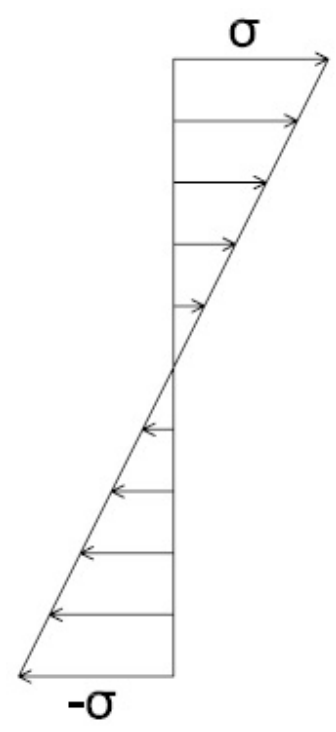

(a)

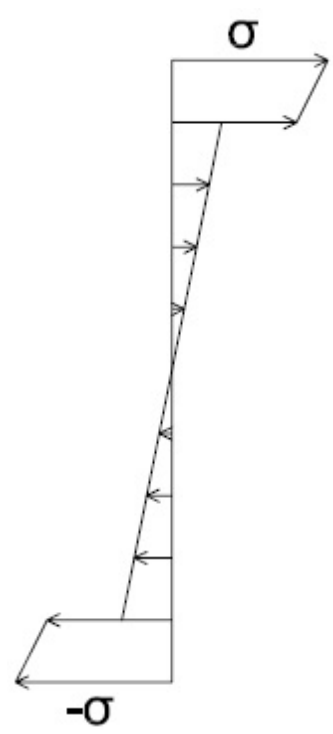

(b)

Figure 3: (a) Stress diagram of homogeneous materials; (b) Estimated stress diagram of Sandwich Panels (Gross et al., 2011) 


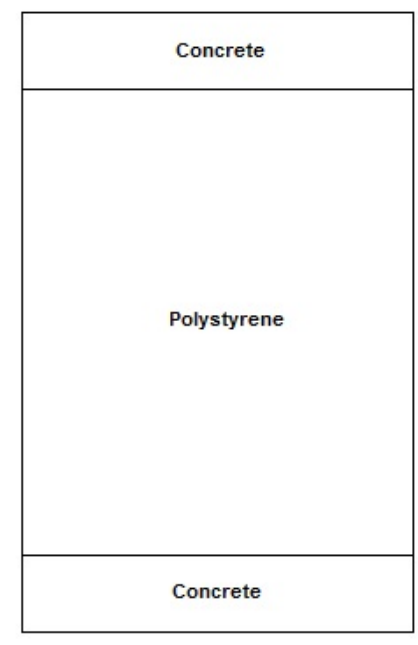

(a)

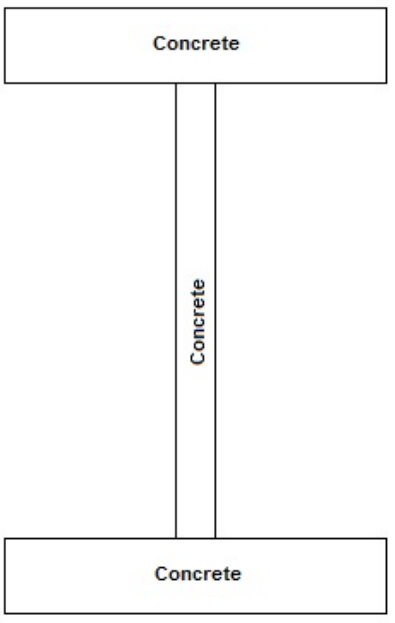

(b)

Figure 4: Cross section of sandwich panels; (a) typical sandwich panels constructed from polystyrene \& concrete with different elastic moduli; (b) converted sandwich panels with one elastic modulus Panels (Gross et al., 2011) 


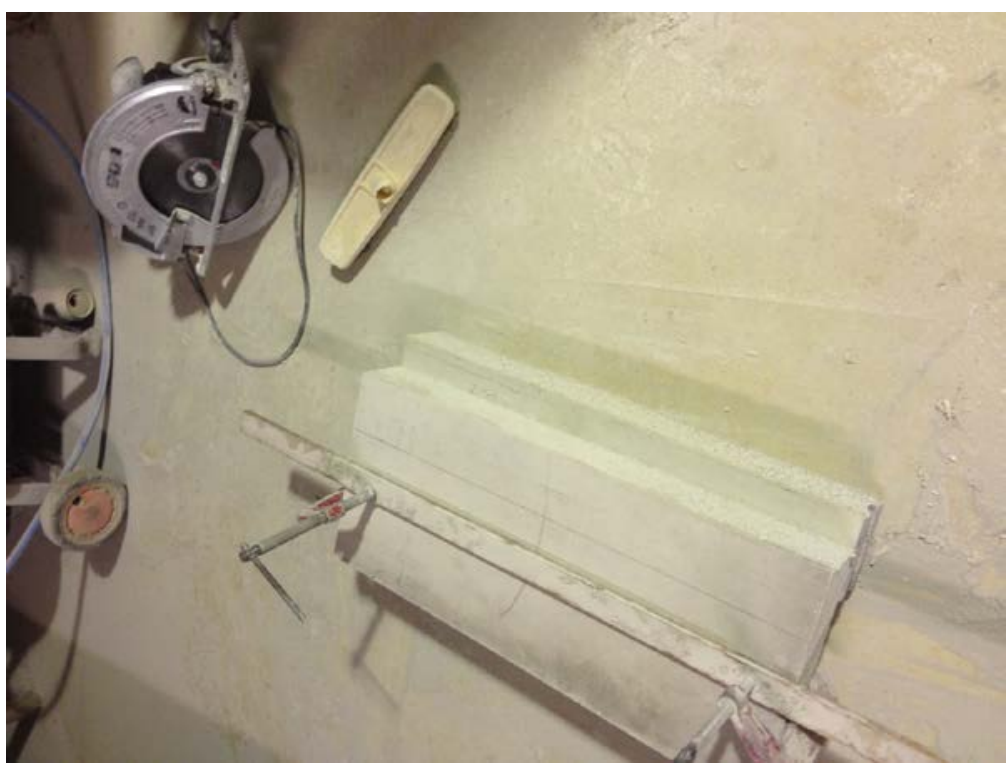

Figure 5: Measuring and cutting of full panels 


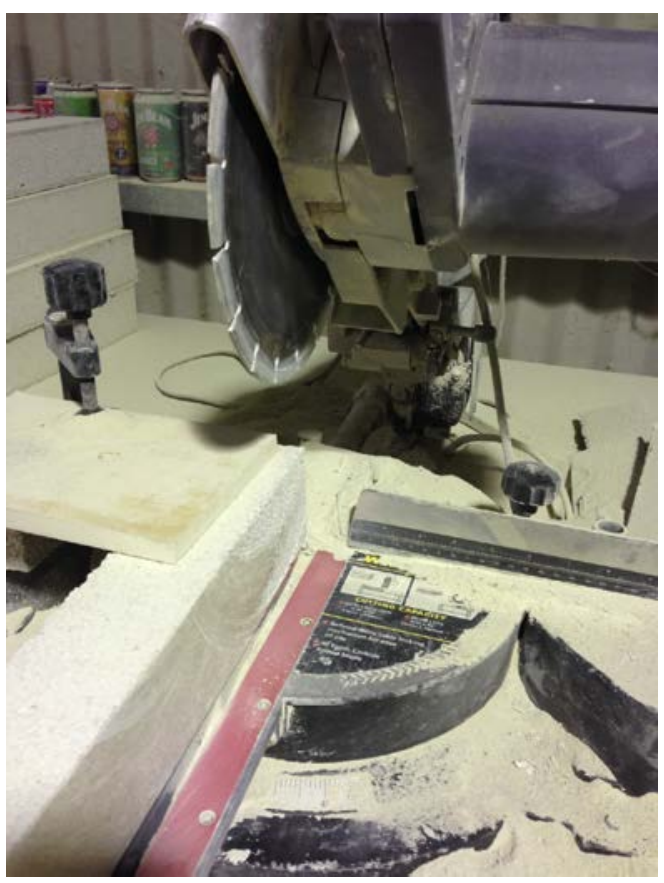

Figure 6: Cutting cement sheeting off core 


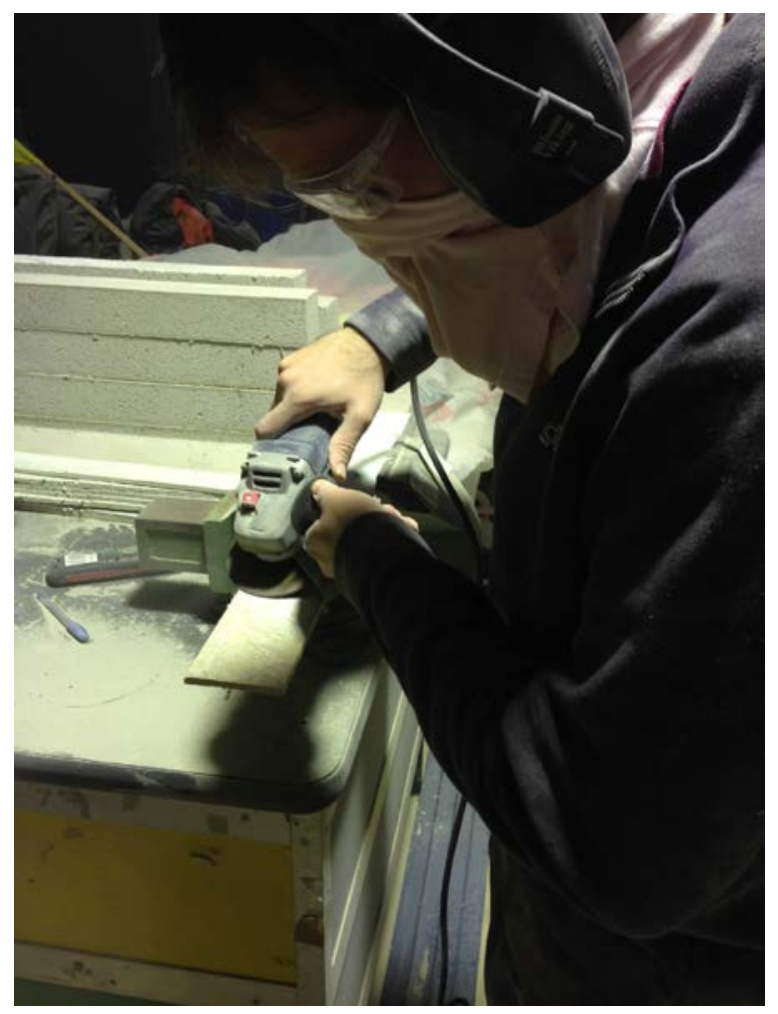

Figure 7: Grinding off the excess core material 


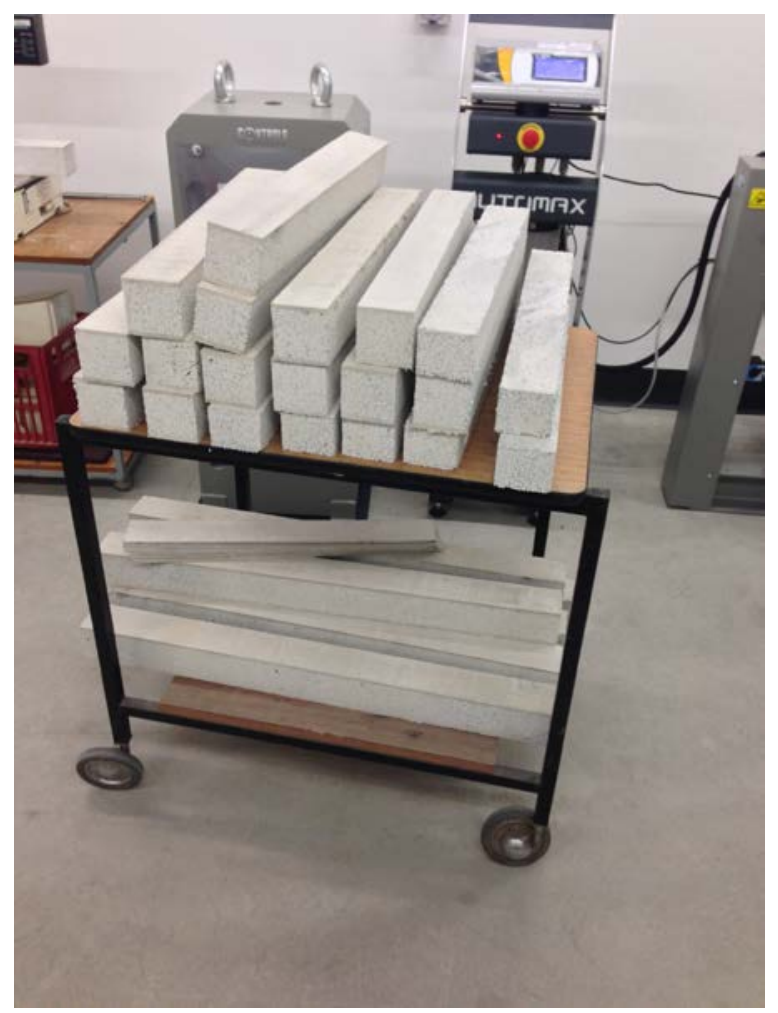

Figure 8: Prepared test samples 


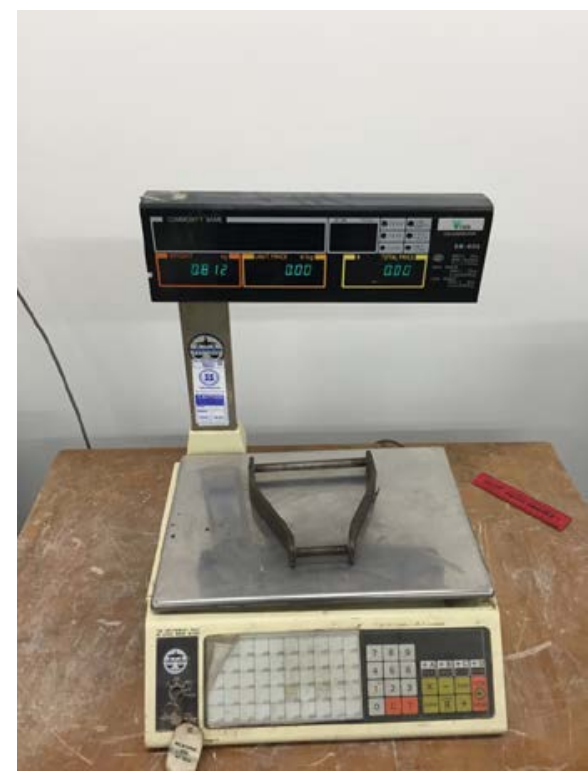

(a)

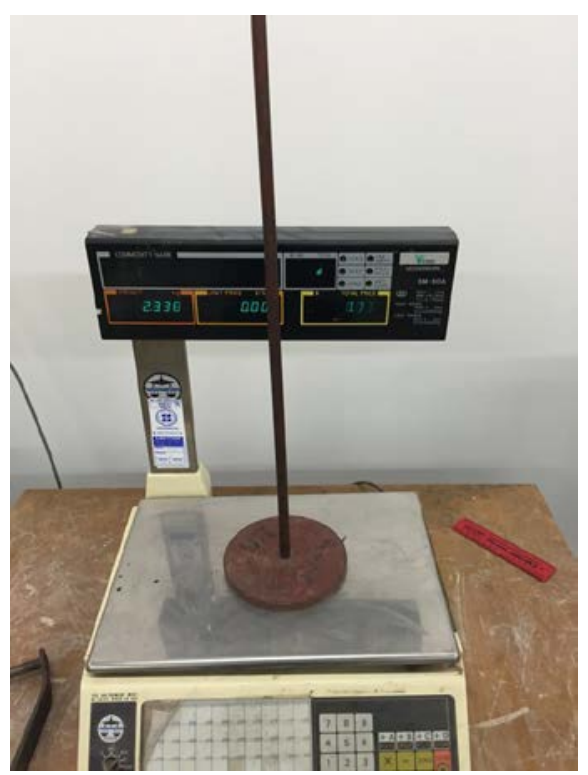

(b)

Figure 9: (a) Hanger 1; (b) Hanger 2 


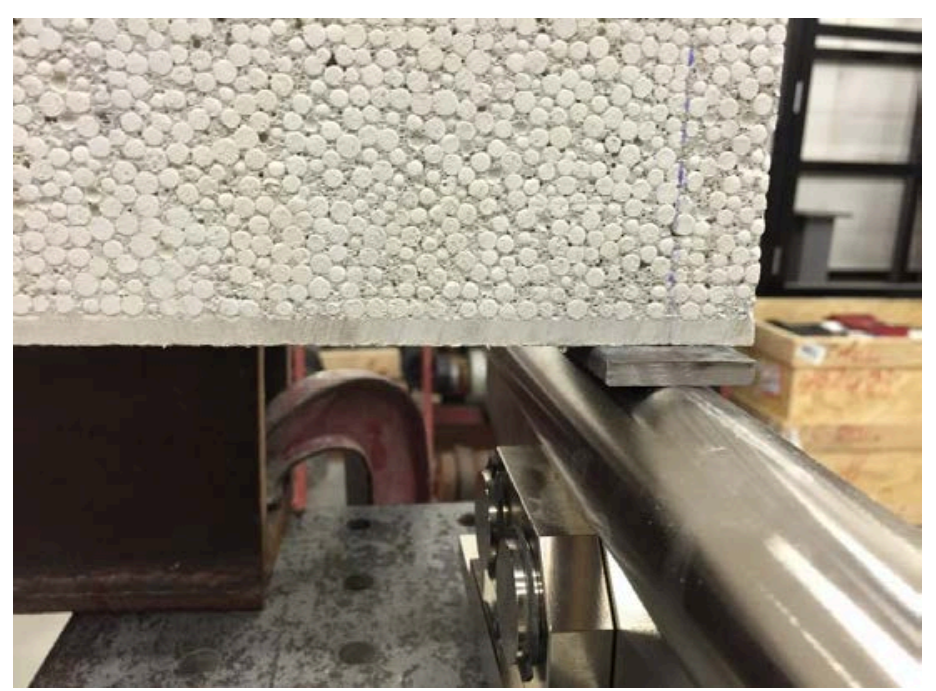

(a)

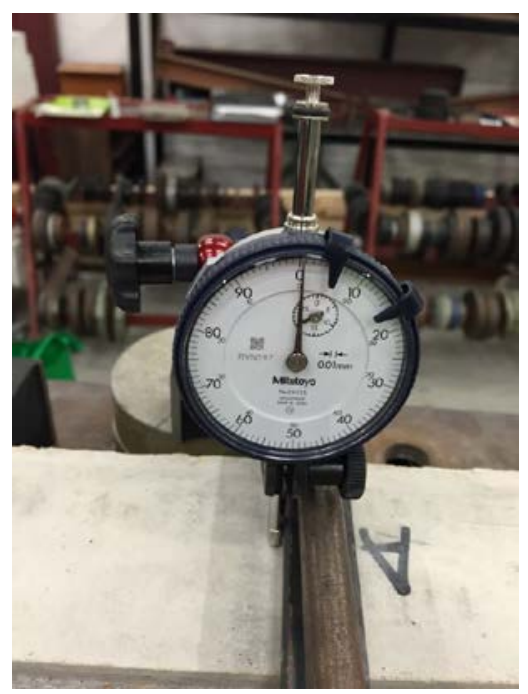

(b)

Figure 10: (a) Support with flat steel; (b) Mid-span deflectometer 


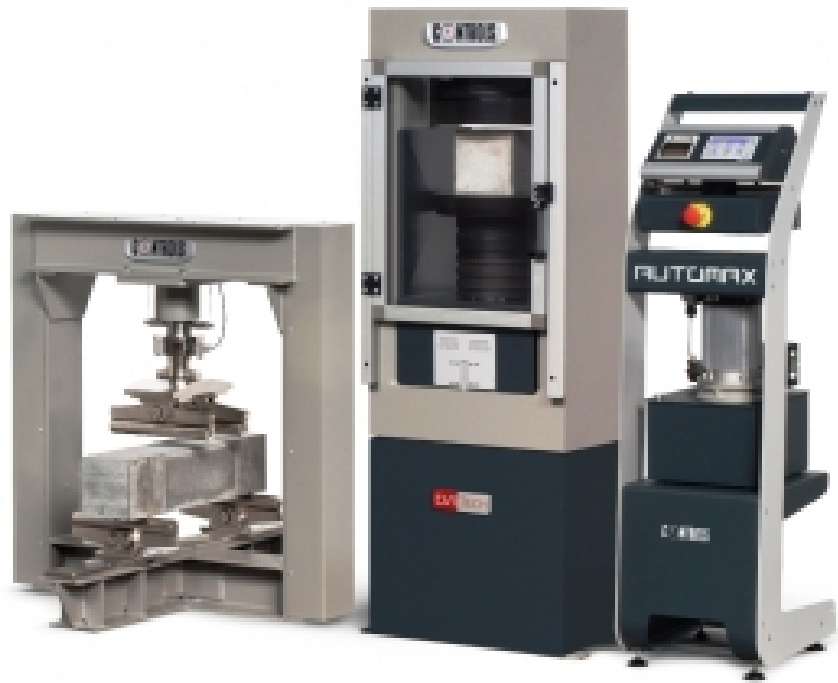

Figure 11: Automax Smart line control system with compression and flexure frames 


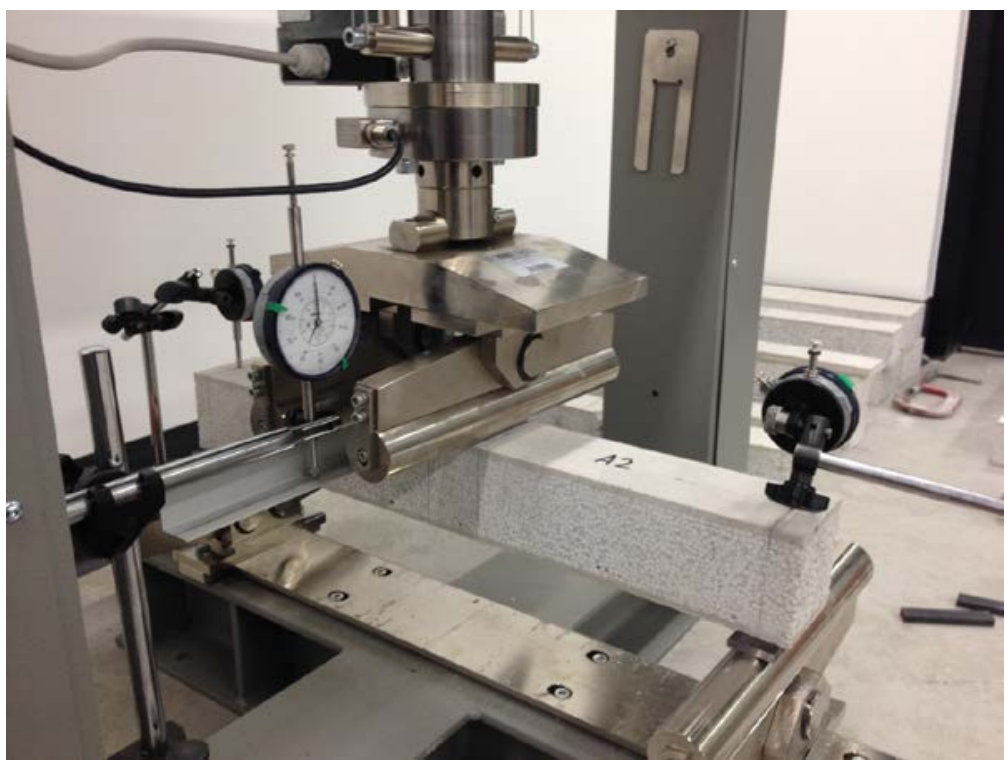

Figure 12: Setup in horizontal flexure test machine 


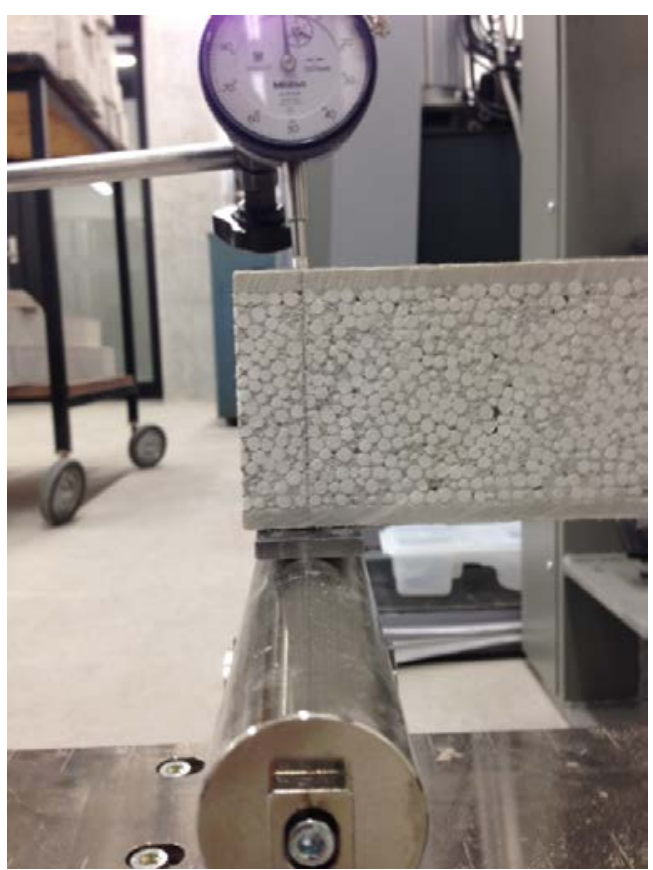

Figure 13: Flat steel between sample and the round support 


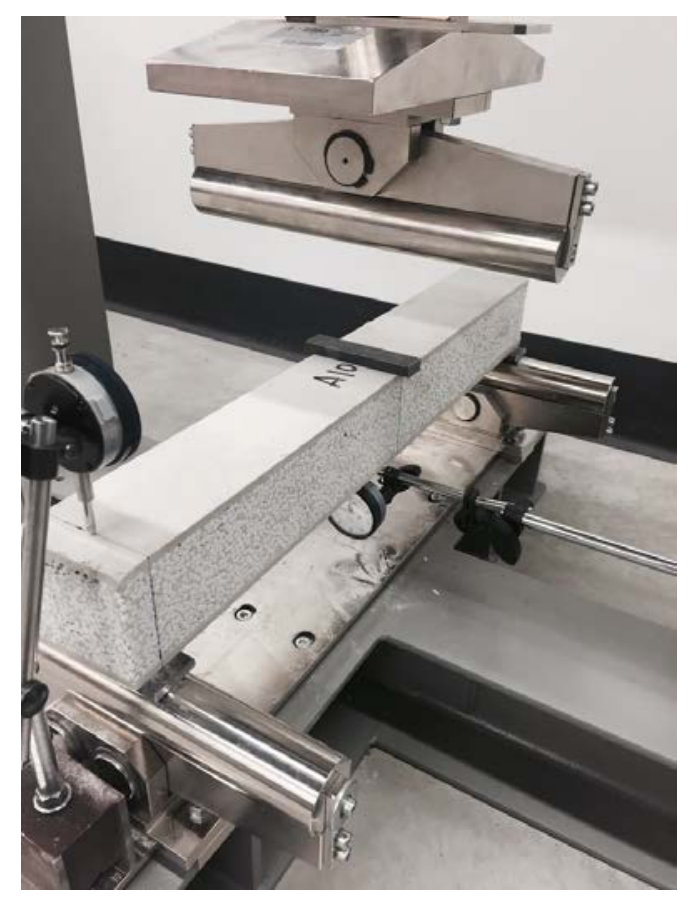

Figure 14: 3-point test in Automax control flexure frame 


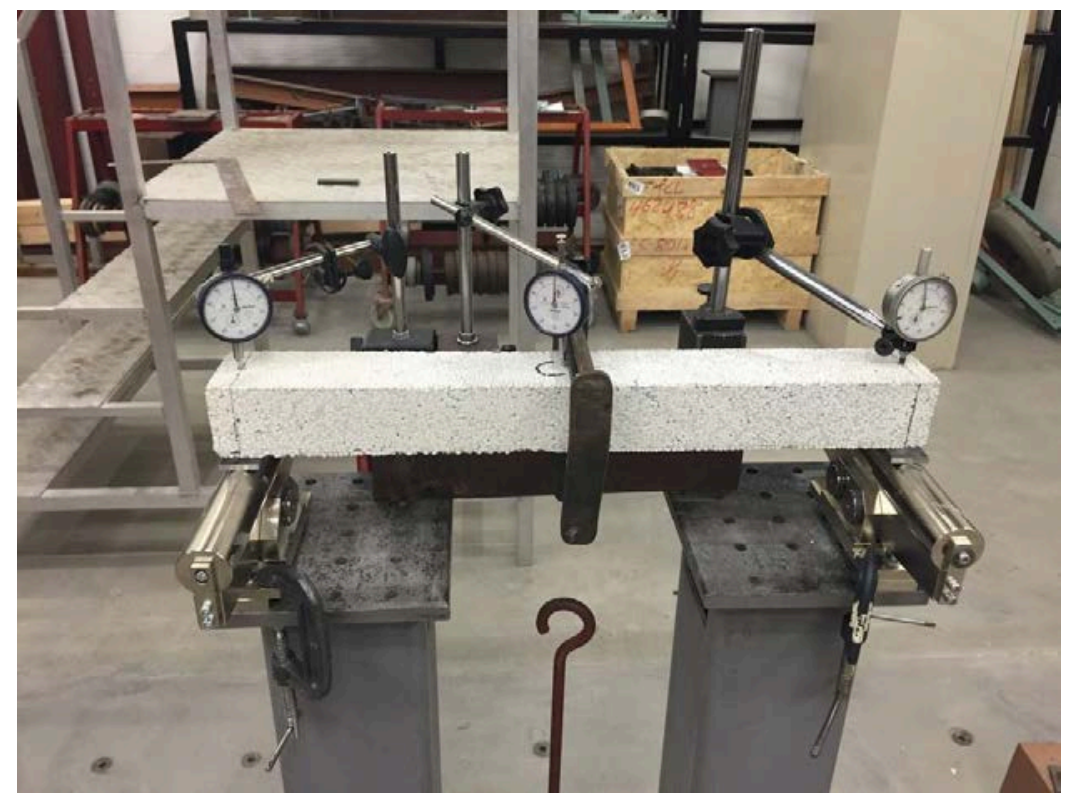

Figure 15: 3-point testing apparatus of core 


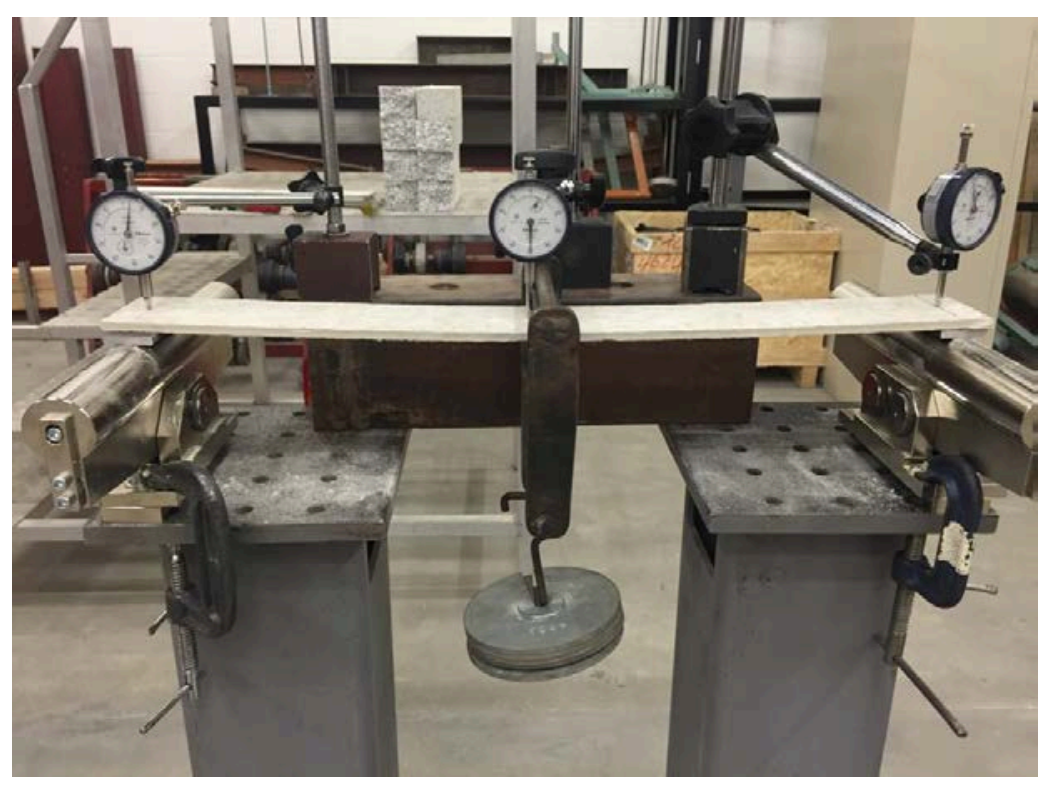

Figure 16: Face Sheeting tensile testing apparatus 


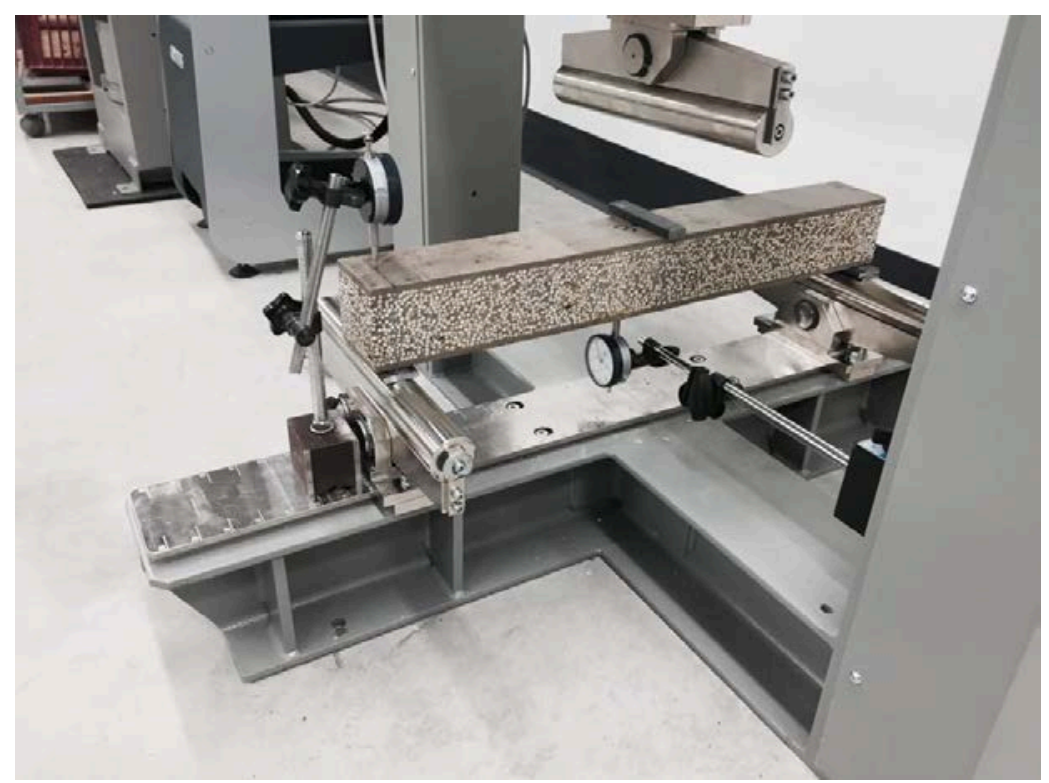

Figure 17: Saturated sample in 3-point loading using Automax control system and the flexure frame apparatus 


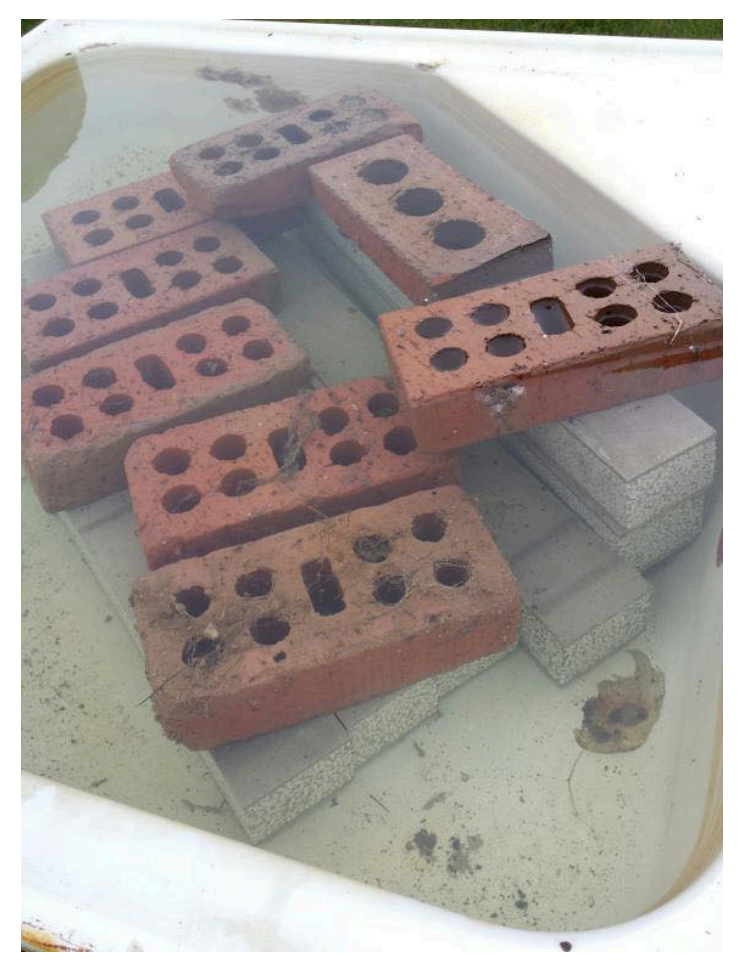

Figure 18: Submerged samples with bricks 


\section{Core Samples - 3 Point}

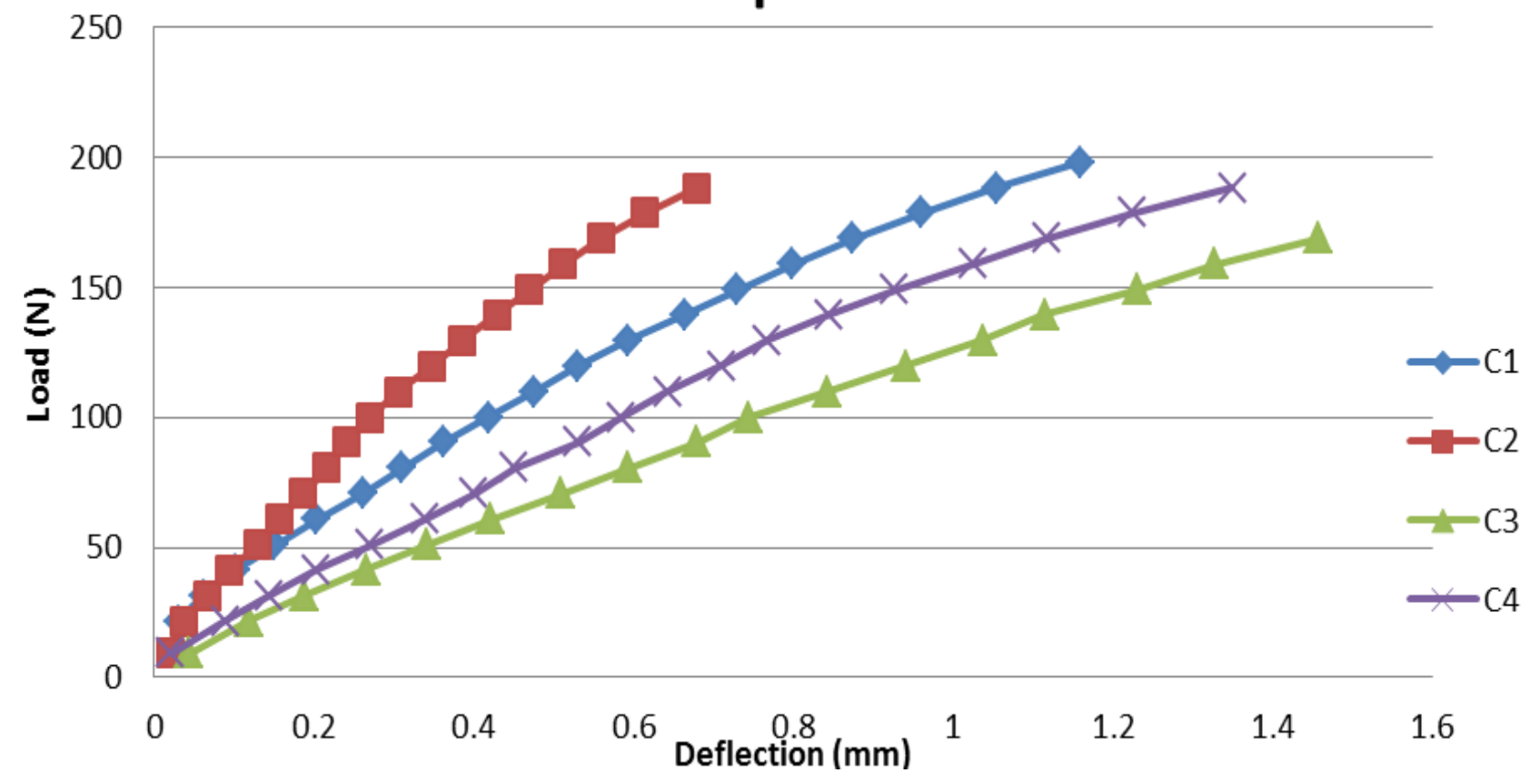

Figure 19: The load-deflection results for four different core samples 
Face Sheeting - 3 Point

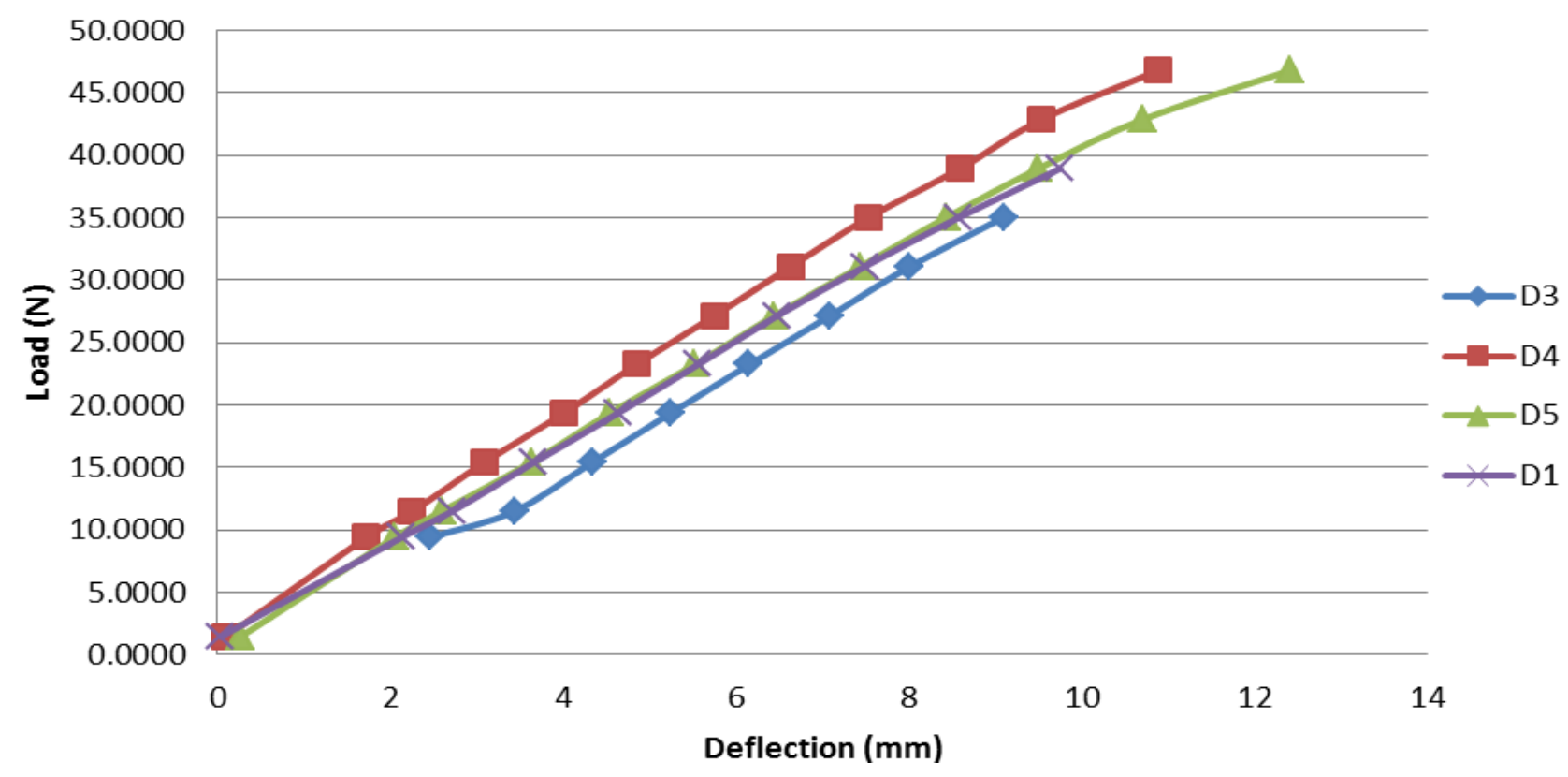

Figure 20: The load-deflection results for four different sheeting samples 


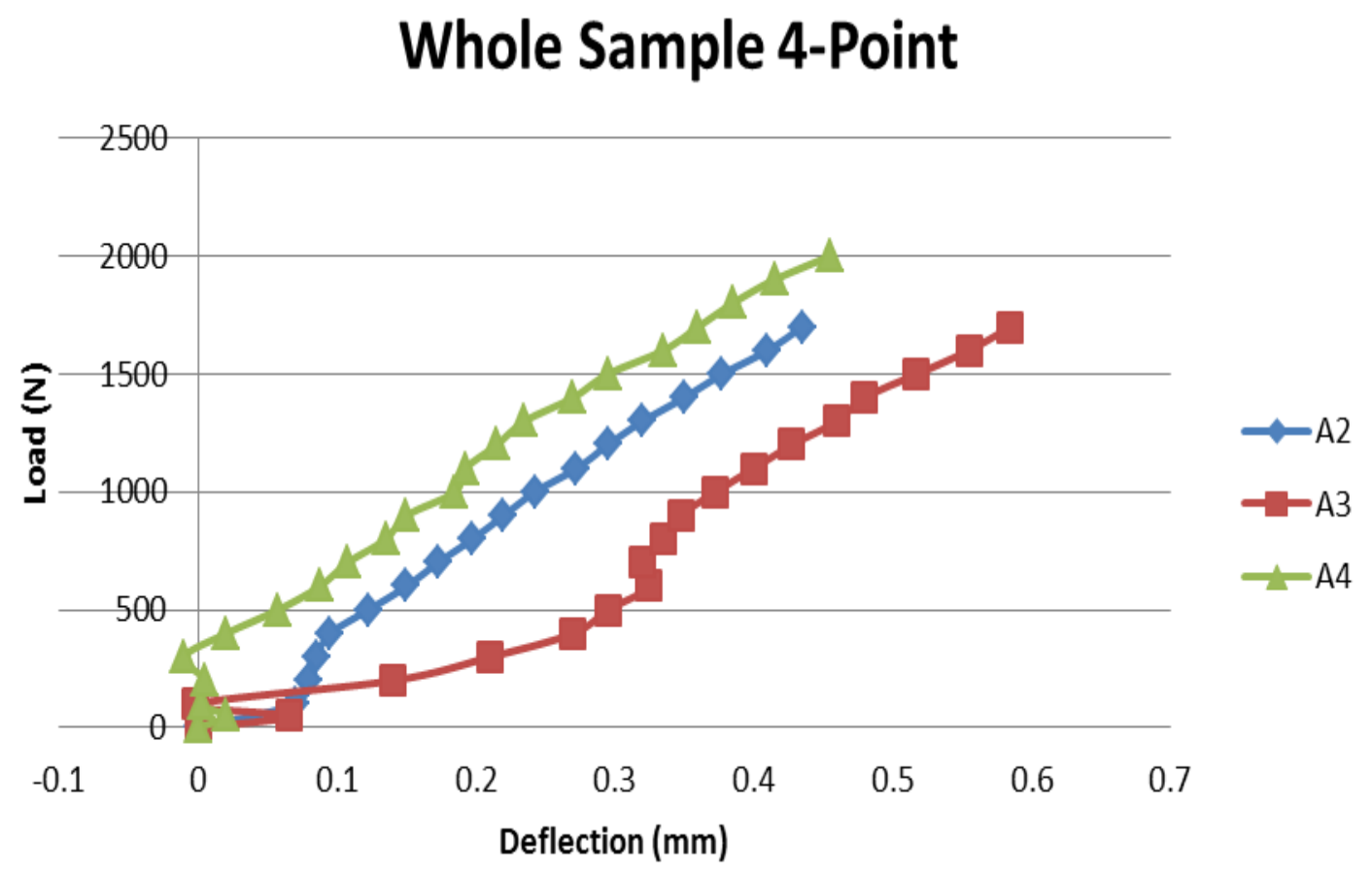

Figure 21: 4-Point Loading Results for three different whole samples 


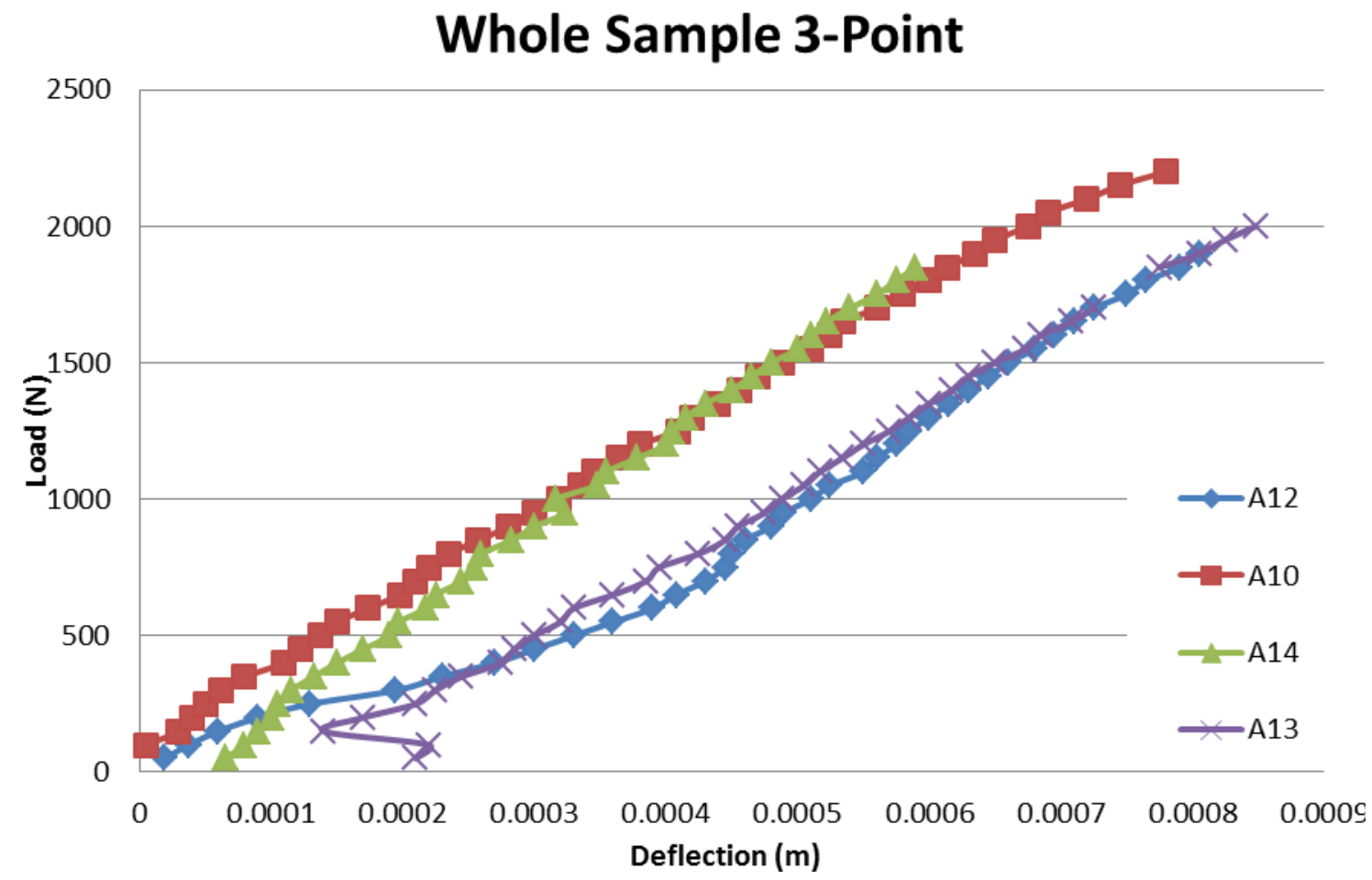

Figure 22: 3-Point loading results for four different whole samples 


\section{Stress Diagram at Failure (Sample A10)}

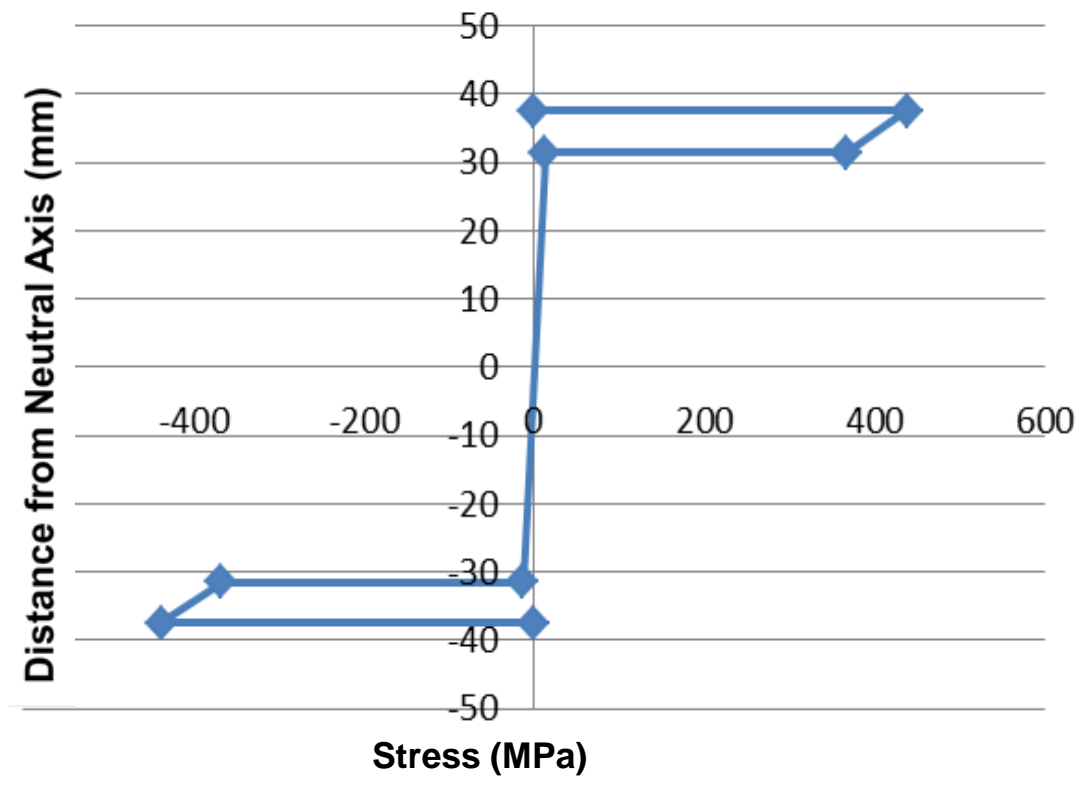

Figure 23: True Stress distribution within the whole panel 


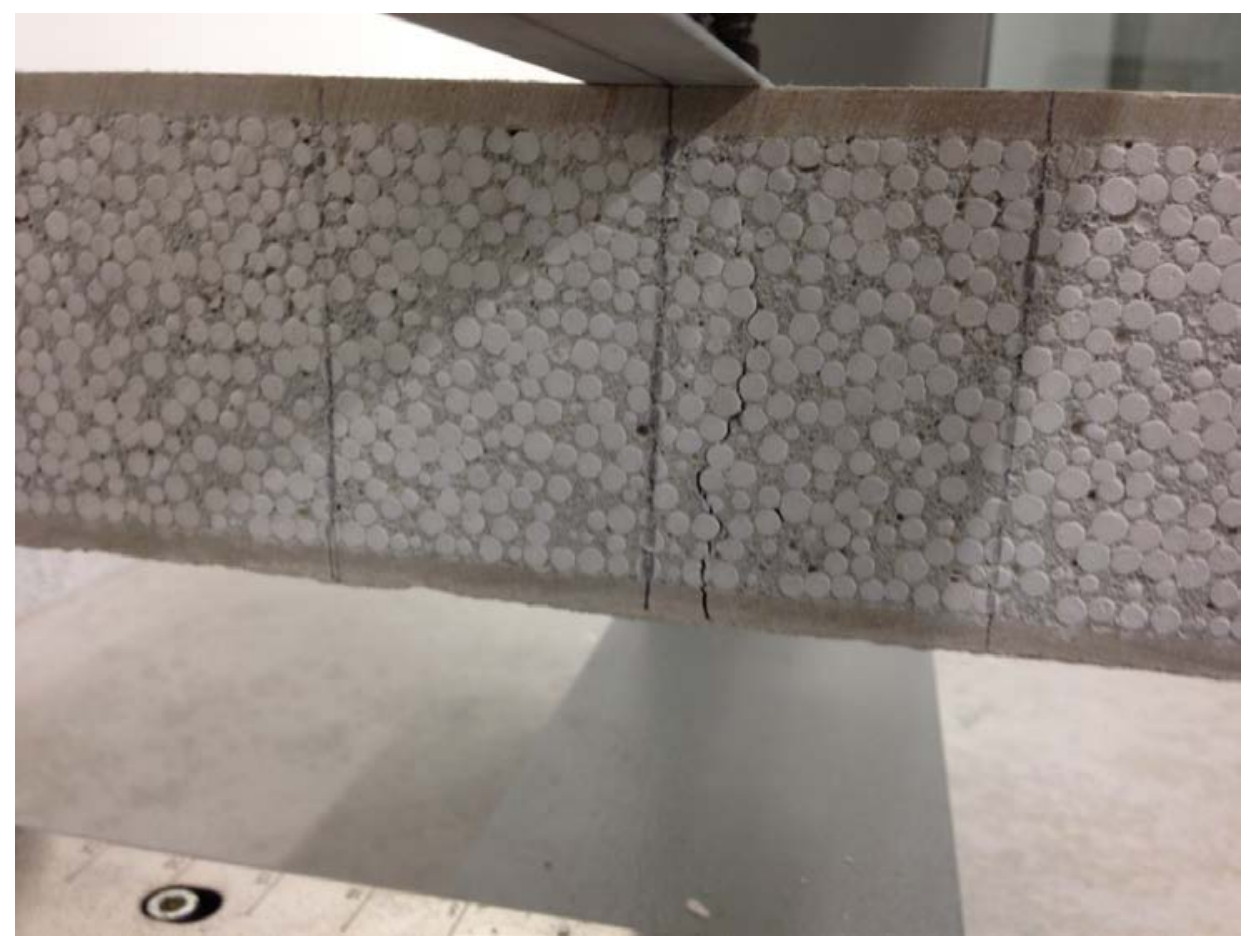

Figure 24: Typical failure of $600 \mathrm{~mm}$ x $75 \mathrm{~mm}$ sample in 4-point loading 


\section{Wet Samples - 3 Point}

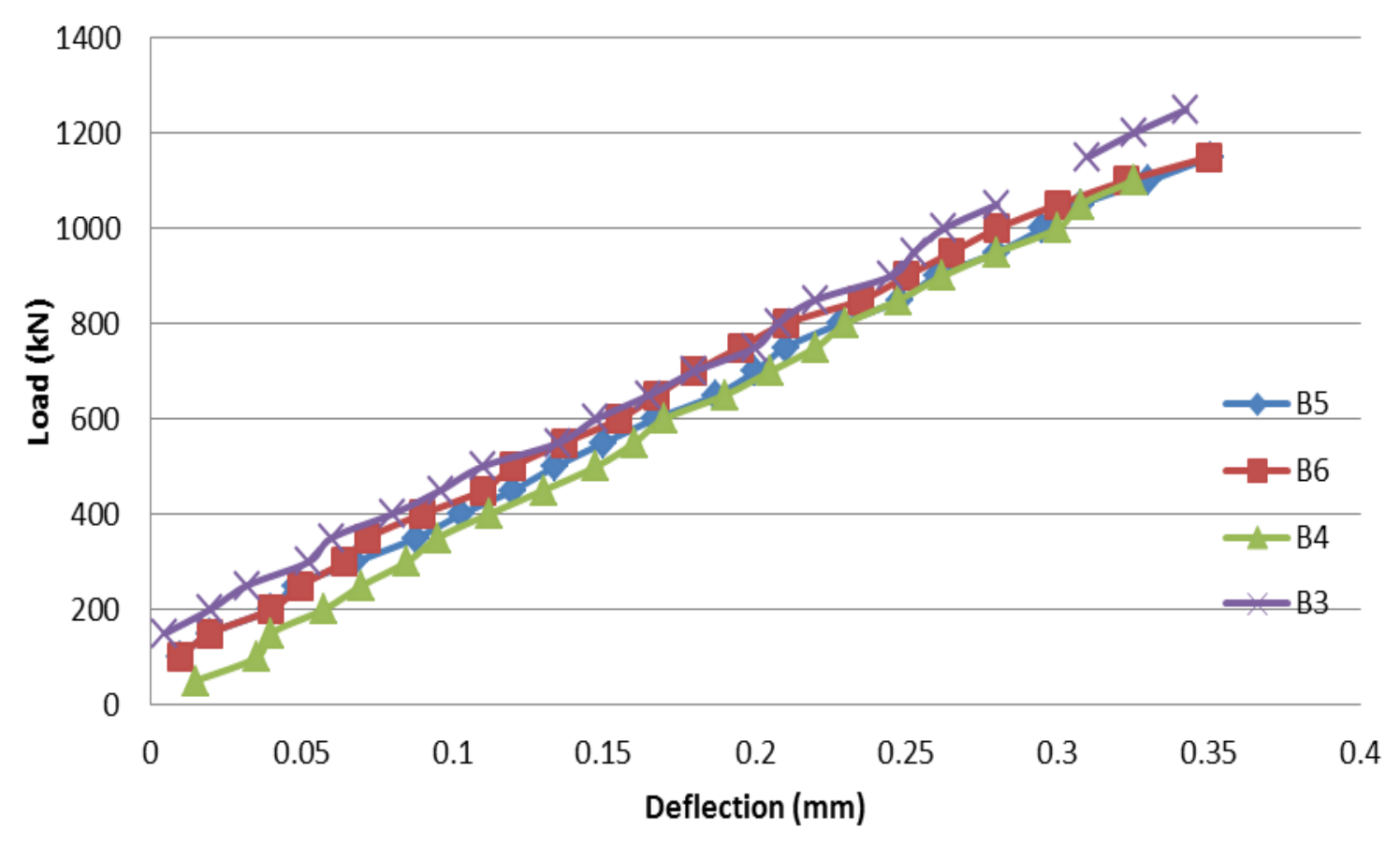

Figure 25: 3-Point loading results for four different saturated samples 


\section{0mm Long Samples}

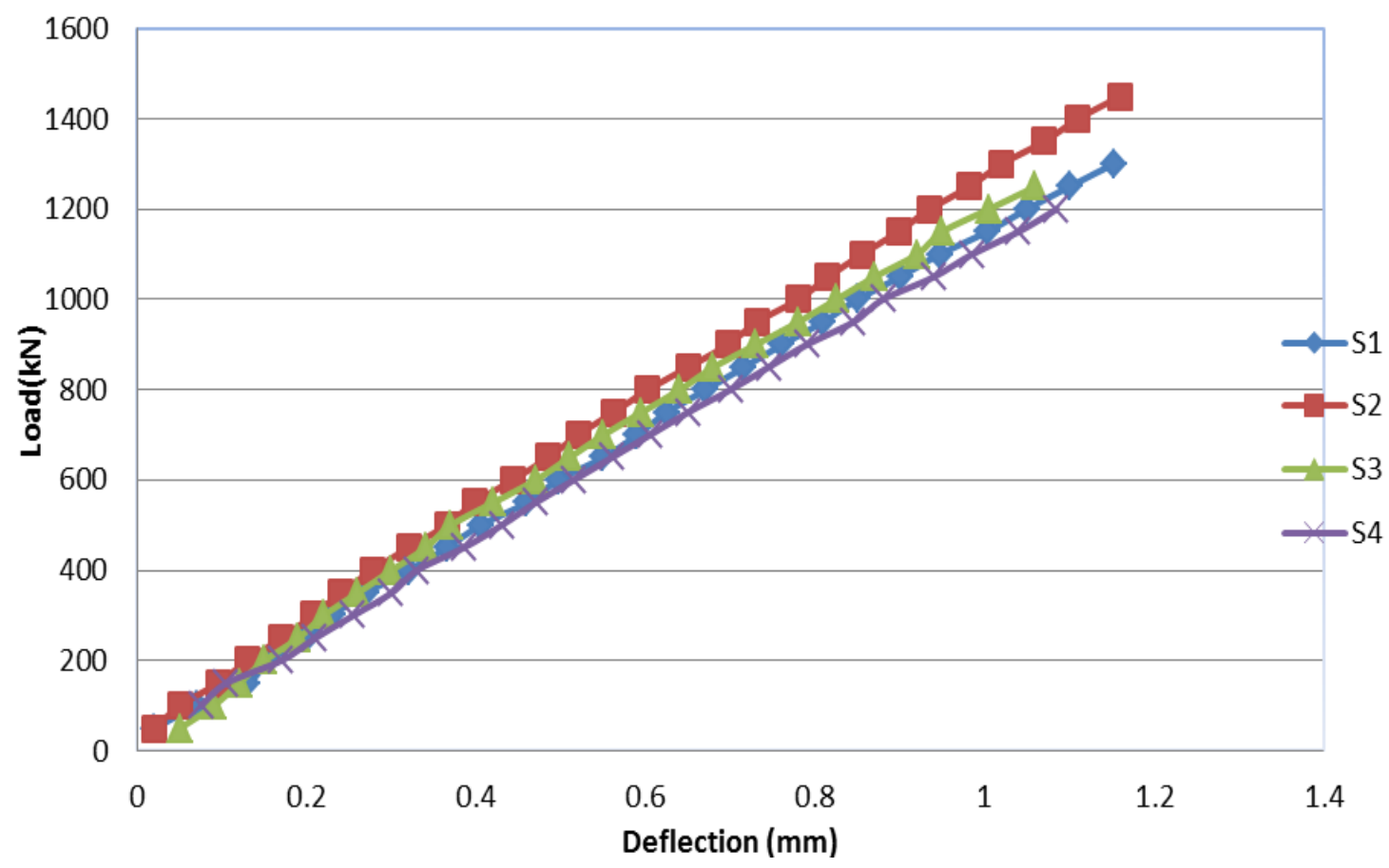

Figure 26: Results of Preliminary Creep Destruction Tests 
Table 1: Moduli of elasticity and ultimate strengths for four different core samples

\begin{tabular}{|c|c|c|c|}
\hline Sample & $\begin{array}{c}\mathbf{y} / \mathbf{x} \\
(\mathbf{N} / \mathbf{m m})\end{array}$ & E (MPa) & Ultimate Strength (N) \\
\hline C1 & 157.92 & 369.7 & 228 \\
\hline $\mathrm{C} 2$ & 273.23 & 639.7 & 218 \\
\hline C3 & 113.07 & 264.7 & 188.5 \\
\hline \multirow[t]{2}{*}{ C4 } & 139.44 & 326.4 & 208 \\
\hline & Average & 400.1 & 210.6 \\
\hline
\end{tabular}


Table 2: Moduli of elasticity and ultimate strengths for four different face sheeting samples

\begin{tabular}{|c|c|c|c|}
\hline Sample & $\begin{array}{c}y / \mathbf{x} \\
(\mathbf{N} / \mathbf{m m})\end{array}$ & E (MPa) & Ultimate Strength (N) \\
\hline D5 & 3.8361 & 10396.3 & 48.6 \\
\hline D1 & 3.9397 & 10677.1 & 58.5 \\
\hline D3 & 4.033 & 10929.9 & 38.95 \\
\hline \multirow[t]{2}{*}{ D4 } & 4.2665 & 11562.7 & 48.6 \\
\hline & Average & 10891.5 & 47.8 \\
\hline
\end{tabular}


Table 3: Moduli of elasticity and ultimate strengths for four different whole samples

\begin{tabular}{|c|c|c|c|}
\hline Sample & $\begin{array}{c}\mathbf{y} / \mathbf{x} \\
(\mathbf{N} / \mathbf{m m})\end{array}$ & E (MPa) & Ultimate Strength $(\mathrm{N})$ \\
\hline A10 & 2796.4 & 3880.2 & 2200 \\
\hline A14 & 3379.1 & 4688.8 & 1900 \\
\hline A12 & 3103.6 & 4306.5 & 1950 \\
\hline \multirow[t]{2}{*}{ A13 } & 2772.7 & 3847.4 & 2000 \\
\hline & Average & 4180.7 & 2000 \\
\hline
\end{tabular}


Table 4: Moduli of elasticity and ultimate strengths for four different saturated whole samples

\begin{tabular}{|c|c|c|c|}
\hline Sample & $\begin{array}{c}\mathbf{y} / \mathbf{x} \\
(\mathbf{N} / \mathbf{m m})\end{array}$ & E (MPa) & Ultimate Strength $(\mathrm{N})$ \\
\hline B3 & 3237.6 & 4492.4 & 1300 \\
\hline B4 & 3375.2 & 4683.4 & 1250 \\
\hline B5 & 3098.6 & 4299.6 & 1350 \\
\hline \multirow[t]{2}{*}{ B6 } & 3163.8 & 4390.0 & 1350 \\
\hline & Average & 4466.4 & 1312.5 \\
\hline
\end{tabular}


Table 5: Preliminary creep test results

\begin{tabular}{cc}
\hline Sample & Ultimate Strength (N) \\
\hline S1 & 1350 \\
\hline S2 & 1550 \\
\hline S3 & 1350 \\
\hline S4 & 1300 \\
\hline Average & 1387.5 \\
\hline $\mathbf{7 5 \%}$ & 1040.625 \\
\hline
\end{tabular}

